\title{
Cross-Flow-Induced-Vibrations in Heat Exchanger Tube Bundles: A Review
}

\author{
Shahab Khushnood et al.* \\ University of Engineering \& Technology, Taxila \\ Pakistan
}

\section{Introduction}

Over the past few decades, the utility industry has suffered enormous financial losses because of vibration related problems in steam generators and heat exchangers. Cross-flow induced vibration due to shell side fluid flow around the tubes bundle of shell and tube heat exchanger results in tube vibration. This is a major concern of designers, process engineers and operators, leading to large amplitude motion or large eccentricities of the tubes in their loose supports, resulting in mechanical damage in the form of tube fretting wear, baffle damage, tube collision damage, tube joint leakage or fatigue and creep etc.

Most of the heat exchangers used in nuclear, petrochemical and power generation industries are shell and tube type. In these heat exchangers, tubes in a bundle are usually the most flexible components of the assembly. Because of cross-flow, tubes in a bundle vibrate. The general trend in heat exchanger design is towards larger exchangers with increased shell side velocities, to cater for the required heat transfer capacity, improve heat transfer and reduce fouling effects. Tube vibrations have resulted in failure due to mechanical wear, fretting and fatigue cracking. Costly plant shutdowns have lead to research efforts and analysis for flow- induced vibrations in cross-flow of shell side fluid. The risk of radiation exposure in steam generators used in pressurized water reactor (PWR) plants demand ultimate safety in designing and operating these exchangers.

(Erskine \& Waddington, 1973) have carried out a parametric form of investigation on a total of nineteen exchanger failures, in addition to other exchangers containing no failures. They realized that these failures represent only a small sample of the many exchangers currently in service. The heat exchanger tube vibration workshop (Chenoweth, 1976) pointed out a critical problem i.e., the information on flow-induced vibration had mostly been withheld because of its proprietary nature.

\footnotetext{
* Zaffar Muhammad Khan'1, Muhammad Afzaal Malik², Zafarullah Koreshi², Muhammad Akram Javaid ${ }^{1}$, Mahmood Anwer Khan ${ }^{3}$, Arshad Hussain Qureshi', Luqman Ahmad Nizam ${ }^{1}$, Khawaja Sajid Bashir ${ }^{1}$, Syed Zahid Hussain ${ }^{1}$ ${ }^{1}$ University of Engineering \& Technology, Taxila, Pakistan

${ }^{2}$ Air University, Islamabad Pakistan

${ }^{3}$ College of Electrical \& Mechanical Engineering NUST, Rawalpindi, Pakistan

${ }_{4}^{4}$ University of Engineering $\mathcal{E}$ Technology, Lahore, Pakistan
} 
Failure of heat exchanger tubes in a bundle due to flow-induced vibrations is a deep concern, particularly in geometrically large and highly rated units. Excessive tube vibration may cause failure by fatigue or by fretting wear. Each tube in a bundle is loosely supported at baffles, forming multiple supports often with unequal support spacing. Reactor components like heat exchanger tubes, fuel rods and piping sections may be modeled as beams on multiple supports. It is important to determine whether any of the natural frequencies be within the operating range of frequencies. Considerable research efforts have been carried out, which highlight the importance of the problem.

Tube natural frequency is an important and primary consideration in flow-induced vibration design. A considerable research has been carried out to calculate the natural frequencies of straight and curved (U-tubes) by various models for single and multiple, continuous spans, in air and in liquids for varying end and intermediate support conditions. (Chenoweth, 1976), (Chen \& Wambsganss, 1974), (Shin \& Wambsganss,1975), (Wambsganss, et al., 1974), (Weaver, 1993), (Brothman, et al., 1974), (Lowery \& Moretti, 1975), (Elliott \& Pick, 1973), (Jones, 1970), (Ojalvo \& Newman, 1964) and (Khushnood et al., 2002), to name some who have carried out research and highlighted the importance of the calculation of natural frequencies of heat exchanger tubes in a bundle.

The dimensionless parameters required for modeling a system may be determined as follows (Weaver, 1993):

- Through non-dimensionalizing the differential equations governing the system behavior.

- From application of Buckingham Pi-theorem.

- This theorem only gives the number of $\pi s$, and not a calculation procedure. So we rely on (i) essentially.

(Shin \& Wambsganss, 1975), and (Khushnood et al., 2000) gave the basics of model testing via dimensional analysis. (Blevins, 1977) has described non-dimensional variables such as geometry, reduced velocity, dimensionless amplitude, mass ratio, Reynolds number and damping factor as being useful in describing the vibrations of an elastic structure in a subsonic steady flow. However, other non-dimensional variables such as Mach number, capillary number, Richardson number, Strouhal number and Euler number are also useful in case effects such as surface tension, gravity, supersonic flow or vortex shedding are also considered.

It is generally accepted that the tube bundle excitation mechanisms are (Weaver, 1993, Pettigrew et al., 1991)

- Turbulent buffeting

- Vorticity excitation

- Fluid-elastic excitation

- Acoustic resonance

Turbulent buffeting cannot be avoided in heat exchangers, as significant turbulence levels are always present. Vibration at or near shedding frequency has a strong organizing effect on the wake. Vorticity or vortex shedding or periodic wake shedding is a discrete, periodic, and a constant Strouhal number phenomenon. Strouhal number is the proportionality constant between the frequency of vortex shedding and free stream velocity divided by 
cylinder width. Fluid-elastic instability is by far the most dangerous excitation mechanism and the most common cause of tube failure. This instability is typical of self-excited vibration in that it results from the interaction of tube motion and flow. Acoustic resonance is caused by some flow excitation (possibly vortex shedding) having a frequency, which coincides with the natural frequency of the heat exchanger cavity.

With regard to dynamic parameters, including added mass and damping, the concept of added mass was first introduced by DuBuat in 1776 (Weaver, 1993). The fluid oscillating with the tube may have an appreciable affect on both natural frequency and mode shape. Added mass is a function of geometry, density of fluid and the size of the tube (Moretti \& Lowry, 1976). Several studies including (Weaver, 1993, Lowery, 1995, Jones, 1970, Chen et al., 1994, Taylor et al., 1998, Rogers et al., 1984, Noghrehkar et al., 1995, Carlucci, 1980, Pettigrew et al., 1994, Pettigrew et al., 1986, Zhou et al., 1997) have targeted damping in heat exchanger tube bundles in single-phase and two-phase cross-flow. (Rogers et al., 1984) have given identification of seven separate sources of damping.

(Ojalvo \& Newman, 1964) have presented design for out-of-plane and in-plane frequency factors for various modes. (Jones, 1970) carried out experimental and analytical analysis of a vibrating beam immersed in a fluid and carrying concentrated mass and rotary inertia. (Erskine \& Waddington, 1973) conducted parametric form of investigation on a total of 19 exchanger failures along with other exchangers containing no failures, for comparative purpose, indicated the incompleteness of methods available till then and emphasized the need for a fully comprehensive design method. Finite element technique applied by (Elliott \& Pick, 1973), concluded that the prediction of natural frequencies was possible with this method and that catastrophic vibrations might be prevented by avoiding matching of material and excitation frequencies. Lack of sufficient data to support comprehensive analytical description for several fundamentally different vibration excitation mechanisms for tube vibration have been indicated in Ontario Hydro Research Division Report (Simpson \& Hartlen, 1974). The report also gives response in terms of mid-span amplitude to a uniformly distributed lift for a simply supported tube. A simple graphical method for predicting the in-plane and out-of-plane frequencies of continuous beams and curved beams on periodic, multiple supports with spans of equal length have been presented by (Chen \& Wambsganss, 1974). They have given design guidelines for calculating natural frequencies of straight and curved beams. (Wambsganss, et al., 1974) have carried out an analytical and experimental study of cylindrical rod vibrating in a viscous fluid, enclosed by a rigid, concentric cylindrical shell, obtaining closed-form solution for added mass and damping coefficient. (Shin \& Wambsganss, 1975) have given information for making the best possible evaluation of potential flow-induced vibration in LMFBR steam generator focusing on tube vibration. A simple computer program developed by (Lowery \& Moretti, 1975), calculates frequencies of idealized support with multiple spans. (Chenoweth, 1976), in his final report on heat exchanger tube vibration, pointed out the slow progress and inadequacy of existing methods and a need for field data to test suitability of design procedures. It stressed the need for testing specially built and instrumented industrial- sized heat exchangers and wind tunnel based theories to demonstrate interaction of many parameters that contribute to flow-induced vibrations. (Rogers et al., 1984) have modeled mass and damping effects of surrounding fluid and also the effects of squeeze film damping. (Pettigrew et.al., 1986) have treated damping of multi-span heat exchanger tubes in air and gases in terms of different 
energy dissipation mechanisms, showing a strong relation of damping to tube support thickness.

(Price, 1995) has reviewed all known theoretical models of fluid-elastic instability for cylinder arrays subject to cross-flow with particular emphasis on the physics of instability mechanisms. Despite considerable difference in the theoretical models, there has been a general agreement in conclusions. (Masatoshi et al., 1997) have carried tests on an intermediate heat exchanger with helically coiled tube bundle using a partial model to investigate the complicated vibrational behavior induced by interaction through seismic stop between center pipe and tube bundle. They have indicated the effect of the size of gap between seismic stop and tube support of the bundle.(Botros \& Price, 2000) have carried out a study of a large heat exchanger tube bundle of styrene monomer plant, which experienced severe fretting and leaking of tubes and considerable costs associated with operational shutdowns. Analysis through Computational Fluid Dynamics (CFD) and fluid-elastic instability study resulted in the replacement of a bundle with shorter span between baffles, and showed no signature of vibration over a wide range of frequencies. (Yang, 2000) has postulated that crossingfrequency can be used as a measure of heat exchanger support plate effectiveness. Crossingfrequency is the number of times per second the vibrational amplitude crosses the zero displacement line from negative displacement to positive displacement.

The wear of tube due to non-linear tube-to-tube support plate (TSP) interactions is caused by the gap clearances between the two interacting components. Tube wall thickness loss and normal work-rates for different TSP combination studies have been the target. Electric Power Research Institute (EPRI), launched an extensive program in early 1980's for analyses of fluid forcing functions, software development and studying linear and nonlinear tube bundle dynamics. Other studies include (Rao et al., 1988), (Axisa \& Izquierdo, 1992), (Payen et al., 1995), (Peterka, 1995), (Hassan et al., 2000), (Charpentier and Payen, 2000) and (Au-Yang, 1998).

Generally, there are three geometric configurations in which tubes are arranged in a bundle. These are triangular, normal square and rotated square. Relatively little information exists on two-phase cross-flow induced vibration. Not surprisingly as single-phase flow-induced vibration is not yet fully understood. Vibration in two-phase is much more complex because it depends upon two-phase flow regime and involves an important consideration, the void fraction, which is the ratio of volume of gas to the volume of the liquid gas mixture. Two-phase flow experimentation is much more expensive and difficult to carry out usually requiring pressurized loops with the ability to produce two-phase mixtures of desired void fractions.

Two-phase flow research includes the models, such as, Smith Correlation (Smith, 1968), driftflux model developed by (Zuber and Findlay, 1965), Schrage correlation (Schrage, 1988), and Feenstra model (Feentra et al., 2000). (Frick et al., 1984) has given an overview of tube wearrate in two-phase flow. (Pettigrew et al., 2000), (Mirza \& Gorman, 1973), (Taylor et al.,1989), (Papp, 1988), (Wambsganss et al., 1992) and others have carried out potential research for vibration response. Earlier reviews on two-phase cross flow are provided by (Paidoussis, 1982), (Weaver \& Fitzpatrik, 1988), (Price, 1995), and (Pettigrew \& Taylor, 1994).

Two-phase cross-flow induced vibration in tube bundles of process heat exchangers and Ubend region of nuclear steam generators can cause serious tube failures by fatigue and fretting wear. Tube failures could force entire plant to shut down for costly repairs and suffering loss of production. Vibration problems may be avoided by thorough vibration 
analysis. However, this requires an understanding of vibration excitation and damping mechanism in two-phase flow. A number of flow regimes (Table 1) can occur for a given boundary configuration, depending upon the concentration and size of the gas bubbles and on the mass flow rates of the two-phases. Two-phase (khushnood, et al., 2004) flow characteristics greatly depend upon the type of flow occurring.

\begin{tabular}{|c|c|l|}
\hline $\begin{array}{c}\text { Flow } \\
\text { Type }\end{array}$ & $\begin{array}{c}\text { Average Void } \\
\text { Fraction }\end{array}$ & \multicolumn{1}{c|}{ Specification } \\
\hline Bubble & $\sim 0.3$ & $\begin{array}{l}\text { Some bubbles are present in liquid flow and move with the } \\
\text { same velocity. }\end{array}$ \\
\hline Slug & $0.3-0.5$ & Liquid slugs flow intermittently. \\
\hline Froth & $0.5-0.8$ & More violent intermittent flow. \\
\hline Annular & $0.8-0.9$ & Mainly gas flow. Liquid adheres to the tube surface. \\
\hline Mist & $\sim 0.9$ & Almost gas flow. Mist sometimes causes energy dissipation. \\
\hline
\end{tabular}

Table 1. Types of Flow in Two-Phases (khushnood, et al., 2004)

Vibration of tube in two-phase flow displays different flow regimes i.e., gas and liquid phase distributions, depending upon the void fraction and mass flux. It is known that four mechanisms are responsible for the excitation of tube arrays in cross-flow (Pettigrew, et al., 1991). These mechanisms are: turbulence buffeting, vortex shedding or Strouhal periodicity, fluid-elastic instability and acoustic resonance. Table 2 presents a summary of these vibration mechanisms for single cylinder and tube bundles for liquid, gas and liquid-gas two-phase flow respectively. Of these four mechanisms, fluid-elastic instability is the most damaging in the short term, because it causes the tubes to vibrate excessively, leading to rapid wear at the tube supports. This mechanism occurs once the flow rate exceeds a threshold velocity at which tubes become self-excited and the vibration amplitude rises rapidly with an increase in flow velocity.

\begin{tabular}{|c|c|c|c|c|}
\hline $\begin{array}{c}\text { Flow Situation } \\
\text { (Cross-Flow) }\end{array}$ & $\begin{array}{l}\text { Fluid-Elastic } \\
\text { Instability }\end{array}$ & $\begin{array}{l}\text { Periodic } \\
\text { Shedding }\end{array}$ & $\begin{array}{l}\text { Turbulence } \\
\text { Excitation }\end{array}$ & $\begin{array}{c}\text { Acoustic } \\
\text { Resonance }\end{array}$ \\
\hline \multicolumn{5}{|l|}{ Single Cylinder } \\
\hline Liquid & $\circ$ & * & * & $\circ$ \\
\hline Gas & $\circ$ & $\Delta$ & $\Delta$ & $\circ$ \\
\hline Two-phase & $\circ$ & $\circ$ & * & $\circ$ \\
\hline \multicolumn{5}{|l|}{ Tube Bundle } \\
\hline Liquid & * & $\Delta$ & $\Delta$ & $\circ$ \\
\hline Gas & * & $\circ$ & $\Delta$ & * \\
\hline Two-phase & * & $\circ$ & * & $\circ$ \\
\hline
\end{tabular}

\begin{tabular}{|l|l|}
\hline Unlikely & ${ }^{\circ}$ \\
\hline Possible & $\Delta$ \\
\hline Most Important & $*$ \\
\hline
\end{tabular}

Table 2. Vibration Excitation Mechanisms (Pettigrew, et al., 1991) 
Typically, researchers have relied on the Homogeneous Equilibrium Model (HEM) (Feentra et al., 2000) to define important fluid parameters in two-phase flow, such as density, void fraction and velocity. This model treats the two-phase flow as a finely mixed and homogeneous in density and temperature, with no difference in velocity between the gas and liquid phases. This model has been used a great deal because it is easy to implement and is widely recognized which facilitated earlier data comparison. Other models include Smith correlation (Smith, 1968), drift-flux model developed by (Zuber and Findlay, 1965), Schrage Correlation (Schrage, 1988), which is based on empirical data, and Feenstra model (Feentra et al., 2000), which is given in terms of dimensionless numbers.

Dynamic parameters such as added or hydrodynamic mass and damping are very important considerations in two-phase cross-flow induced vibrations. Hydrodynamic mass depends upon pitch-to-diameter ratio and decrease with increase in void fraction. Damping is very complicated in two-phase flow and is highly void fraction dependent. Tube-to-restraint interaction at the baffles (loose supports) can lead to fretting wear because of out of plane impact force and in-plane rubbing force. (Frick et al., 1984) has given an overview of the development of relationship between work-rate and wear-rate. Another important consideration in two-phase flow is the random turbulence excitation. Vibration response below fluid-elastic instability is attributed to random turbulence excitation.

(Pettigrew et al., 2000), (Mirza \& Gorman, 1973), (Taylor et al.,1989), (Papp, 1988), and (Wambsganss et al., 1992) to name some, have carried out research for Root Mean Square (RMS) vibration response, encompassing spatially correlated forces, Normalized Power Spectral Density (NPSD), two-phase flow pressure drop, two-phase friction multiplier, mass flux, and coefficient of interaction between fluid mixture and tubes. More recently researchers have expanded the study to two-phase flow which occur in nuclear steam generators and many other tubular heat exchangers, a review of which was last given by (Pettigrew \& Taylor, 1994). A current review on this topic is given by (Khushnood et al., 2004)

The use of Finite Element Method (FEM), Computational Fluid Dynamics (CFD) and Large Eddy Simulation (LES) have proved quite useful in analyzing flow-induced vibrations in tube bundles in recent years. Earlier on, only pressure drop and heat transfer calculations were considered as the basis of heat exchanger design. Recently, flow-induced tube vibrations have also been included in the design criteria for process heat exchangers and steam generators.

\subsection{Regimes}

(Kim et al., 2009) have carried flow induced vibrations (Experimental study of two circular cylinders in tandem arrangement) and examined three different experimental conditions both cylinders allowed to vibrate, the upstream cylinder is allowed to vibrate with the downstream cylinder fixed and downstream cylinder allowed to vibrate with upstream cylinder fixed. The results include five regimes depending upon $L / D$, fluctuating lift forces and vibration characteristics of the cylinder as given in Table 3. 


\begin{tabular}{|c|c|c|c|c|c|}
\hline Regimes & $\mathrm{I}$ & II & III & IV & $\mathrm{V}$ \\
\hline Range & $\begin{array}{c}0.1 \leq \boldsymbol{L} / \boldsymbol{D} \\
\geq 0.2\end{array}$ & $\begin{array}{c}0.2 \leq \boldsymbol{L} / \boldsymbol{D}^{\geq} \\
0.6\end{array}$ & $\begin{array}{c}0.6 \leq \boldsymbol{L} / \boldsymbol{D}^{\geq} \\
2.0\end{array}$ & $\begin{array}{c}2.0 \leq \boldsymbol{L} / \boldsymbol{D}^{\geq} \\
2.7\end{array}$ & $L / D^{\geq 2.7}$ \\
\hline Response & $\begin{array}{c}\text { Vibration } \\
\text { absent }\end{array}$ & $\begin{array}{c}\text { Violent } \\
\text { vibrations } \\
\text { of both } \\
\text { For } U_{r}>6\end{array}$ & $\begin{array}{c}\text { Convergent } \\
\text { vibrations at } \\
\qquad U_{r} \approx 6.7\end{array}$ & $\begin{array}{c}\text { Vibration } \\
\text { absent }\end{array}$ & $\begin{array}{c}\text { Each vibrating } \\
\text { like isolated } \\
\text { cylinder } \\
\text { at } U_{r} \approx 6.7 \\
\end{array}$ \\
\hline Characteristics & & $\begin{array}{l}\text { Vibration } \\
\text { amplitude } \\
\text { is strongly } \\
\text { dependant } \\
\text { on whether } \\
\text { upstream } \\
\text { cylinder is } \\
\text { fixed or } \\
\text { vibrating }\end{array}$ & $\begin{array}{l}\text { Upstream } \\
\text { cylinder } \\
\text { vibration is } \\
\text { completely } \\
\text { suppressed } \\
\text { when } \\
\text { downstream } \\
\text { cylinder is } \\
\text { fixed but the } \\
\text { downstream } \\
\text { cylinder is } \\
\text { independent } \\
\text { of upstream } \\
\text { cylinder. }\end{array}$ & & $\begin{array}{l}\text { Downstream } \\
\text { vibration is } \\
\text { strongly } \\
\text { dependant on } \\
\text { upstream } \\
\text { cylinder but } \\
\text { upstream } \\
\text { cylinder } \\
\text { vibrations is } \\
\text { insensitive to } \\
\text { downstream } \\
\text { cylinder. }\end{array}$ \\
\hline
\end{tabular}

Table 3. Regimes of vibration for Circular cylinders tandem (Kim, et al., 2009)

\section{Excitation mechanisms}

\subsection{Fluid-elastic instability}

Fluid-elastic instability is by far the most dangerous excitation mechanism in heat exchanger tube bundles and the most common cause of tube failures. The forces associated with fluid- elastic instability exist only because of the motion of the body. (Price, 1995) has presented comprehensive review on fluid-elastic instability of cylinder arrays in cross-flow. According to Price, the nature of fluid-elastic instability can be illustrated as a feedback mechanism between structural motion and the resulting fluid forces. A small structural displacement due to turbulence alters the flow pattern, inducing a change in fluid forces. This in turn leads to a further displacement, and so on. If the displacement increases (positive feedback), then fluid-elastic instability occurs. Three mechanisms (Price, 1995), which enable the cylinder to extract energy from flow:

- $\quad$ require a phase difference between cylinder displacement and fluid force generated.

- relies on there being at least two-degrees of freedom with a phase difference between them.

- because of non-linearities, the fluid force is hysteretic and its magnitude depends on the direction of cylinder motion.

A considerable theoretical and experimental research has been undertaken in the past three decades to arrive at a safe and reliable design criteria against fluid-elastic instability. The topic has been reviewed on regular basis from time to time by various researchers including (Paidoussis, 1980, 1981, 1987, 1987), (Chen, 1984, 1987, 1987, 1989), (Zukauskas et al., 1987), (Weaver \& FitzPatrick, 1988), (Moretti, 1993) and (Price, 1995). 


\subsection{Fluid-elastic instability models}

\subsubsection{Jet switch model}

(Roberts, 1962, 1966) considered both a single and a double row of cylinders normal to flow. His analysis was limited to in-flow motion (experiments indicated that instability was purely in the in-flow direction). Roberts assumed that the flow downstream of two-adjacent cylinders could be represented by two wake regions, one large and one small, and a jet between them as shown in Figure 1.

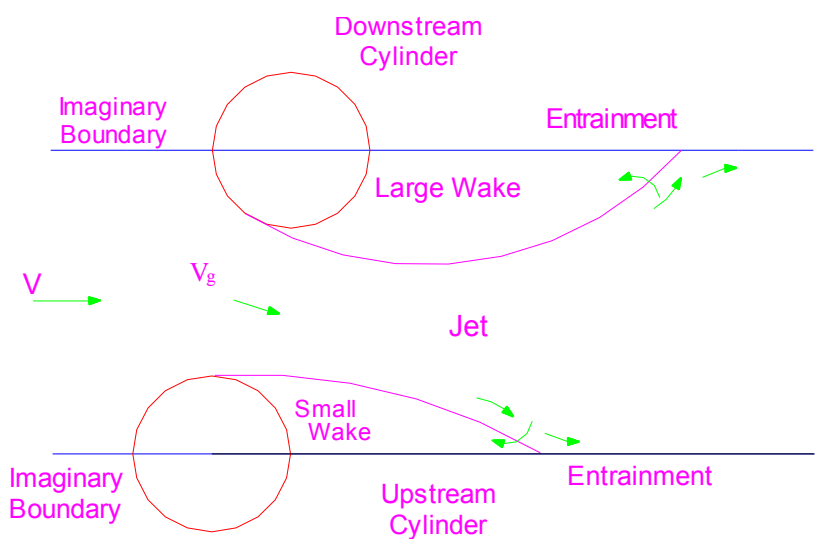

Fig. 1. Idealized model of the jet-flow between two cylinders in a staggered row of cylinders (Roberts, 1962).

Considering a downstream cylinder moving upstream; as the two cylinders cross, insufficient fluid flows in to the large wake region to maintain the entrainment, causing the wake to shrink and the jet to switch directions. Roberts has given the flow equation of motion for a cylinder or tube in a row.

$$
\frac{d^{2} x}{d \tau^{2}}+2 \zeta \frac{d x}{d \tau}+x=\frac{\rho V^{2}}{2 m \omega_{n}^{2}}\left\{0.717\left(1-C_{p b}(x, \tau)-2\left(\frac{\omega_{n} D}{V}\right)\left(1-C_{p b}\right)_{\text {mean }} \frac{d x}{d \tau}\right\}\right.
$$

where $C_{p b}$ is the base pressure coefficient, $\tau$ is non-dimensional time $\left(t \omega_{n}\right), D$ is the tube diameter, $\omega_{n}$ is the natural frequency, $x$ is the in-flow cylinder displacement, $\zeta$ is the damping factor or ratio, $\delta$ is the logarithmic decrement, and $m$ is mass of the tube. Equation 1 was solved using the method of Krylov and Bogoliubov (Minorsky, 1947) giving $V_{c}$, the velocity just sufficient to initiate limit cycle motion for any $m \delta / \rho D^{2}$. Neglecting unsteady terms and fluid damping, the solution reduces to

$$
\frac{V_{c}}{\omega_{n} \varepsilon D}=K\left(\frac{m \delta}{\rho D^{2}}\right)^{0.5}
$$

where $\varepsilon$ is the ratio of fluid-elastic frequency to structural frequency, which is approximately 1.0 and $\rho$ is the fluid density. This has the same form as the classical Connors equation (Blevins, 1979). Figure 2 presents Robert's experimental data for pitch-todia. ratio $(P / D=1.5)$, showing a good agreement with this theoretical model. 


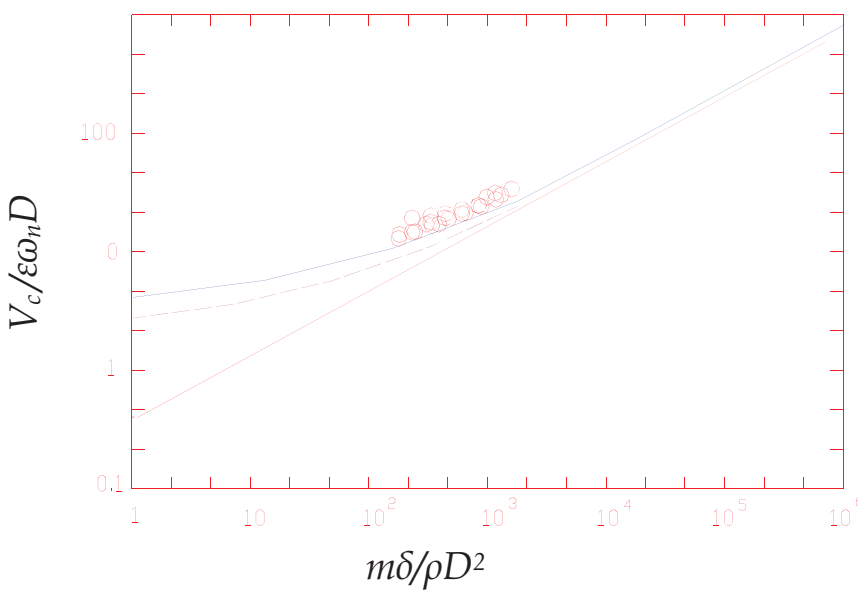

- Solution including time for jet reversal and aerodynamic damping

- - Solution assuming instantaneous jet reversal but still including aerodynamic damping Solution assuming instantaneous jet reversal and neglecting aerodynamic damping

O Roberts' experimental results

Fig. 2. Theoretical stability boundary for fluid-elastic instability obtained by Roberts for a single flexible cylinder in a row of cylinders (Roberts, 1966).

\subsubsection{Quasi-static models}

Using a quasi-static analysis, (Connors \& Parrondo, 1970) and later (Dalton \& Helfinstine, 1971) developed the fluid-elastic instability prediction for cylinders (single row of cylinders) subjected to cross-flow. Connors measured the fluid forces instead of predicting these using pitch to dia. ratio of $\mathrm{P} / \mathrm{D}=1.41$. He observed many different model patterns at instability, but suggested that the most dominant was elliptical motion (whirling). Using the measured fluid stiffness, Connors obtained energy balances in the in-and cross-flow directions, which must be satisfied simultaneously giving

$$
\frac{V_{p c}}{f_{n} D}=K\left(\frac{m \delta}{\rho D^{2}}\right)^{0.5}
$$

where $K$ is the so-called Connors constant, $f_{n}$ is the frequency of oscillation. $V_{p c}$ is the socalled pitch velocity given by

$$
V_{p c}=\frac{V P}{P-D}
$$

where $P$ being the centre-to-centre inter cylinder pitch

(Blevins, 1974) has derived Equation 3 by assuming that the fluid forces on any cylinder are due to relative displacements between itself and its neighboring cylinders. Later, (Blevins, 1979) modified his original analysis to account for flow dependent fluid damping giving 


$$
\frac{V_{p c}}{f_{n} D}=K\left[\frac{m}{\rho D^{2}} 2 \pi\left(\zeta_{x} \zeta_{y}\right)^{1 / 2}\right]^{1 / 2}
$$

where $\zeta_{x}$ and $\zeta_{y}$ are total damping factors in the in-and cross-flow directions.

\subsubsection{In viscid model}

Despite the obviously viscous nature of the interstitial flow through arrays of cylinders, the compactness of some arrays suggests that the cylinder wake regions are small, especially for normal triangular arrays with small P/D (Price, 1995). Hence under this assumption wake regions are neglected and flow is treated as inviscid. Many solutions based upon potential flow theory have been given, including (Dalton \& Helfinstine, 1971), (Dalton, 1980), (Balsa, 1977), (Paidoussis et al., 1984), (Vander Hoogt \& Van Compen, 1984) and (Delaigue \& Planchard, 1986). The results obtained from potential flow analyses are somewhat discouraging (Price, 1995). Recent flow visualizations suggest that even though the wake regions are small, the interstitial flow is more complex than that accounted for in these analyses.

\subsubsection{Unsteady models}

The unsteady models measure the unsteady forces on the oscillating cylinder directly. (Tanaka \& Takahara, 1980, 1981) and (Chen, 1983) have given theoretical stability boundary for fluid-elastic instability as shown in Figures 3 and 4 respectively.

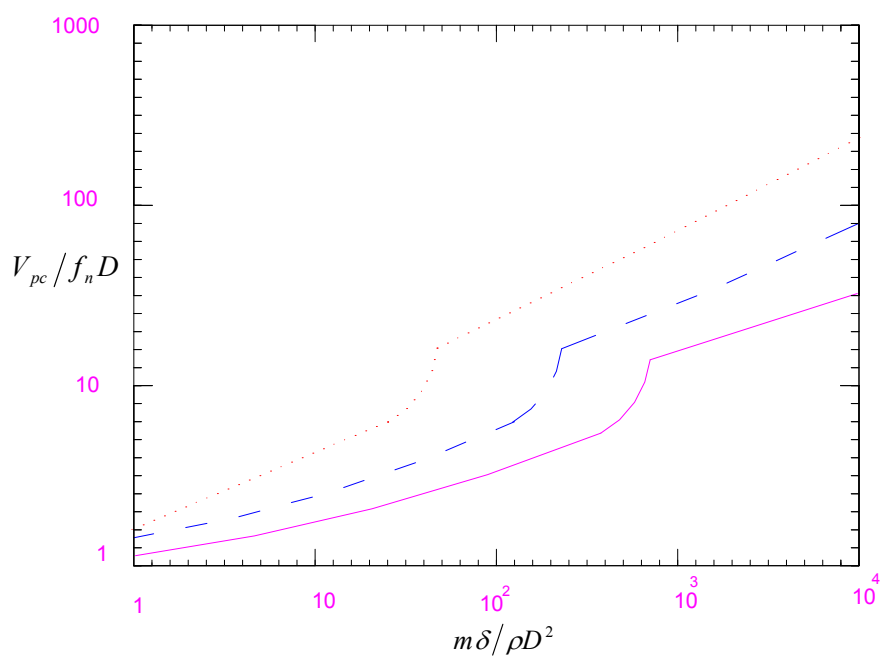

$\delta=0.01$

$---\delta=0.03$

Fig. 3. Theoretical stability boundary for fluid-elastic instability for an in-line square array, $\mathrm{P} / \mathrm{D}=1.33$, obtained by (Tanaka \& Takahara, 1980, 1981). 


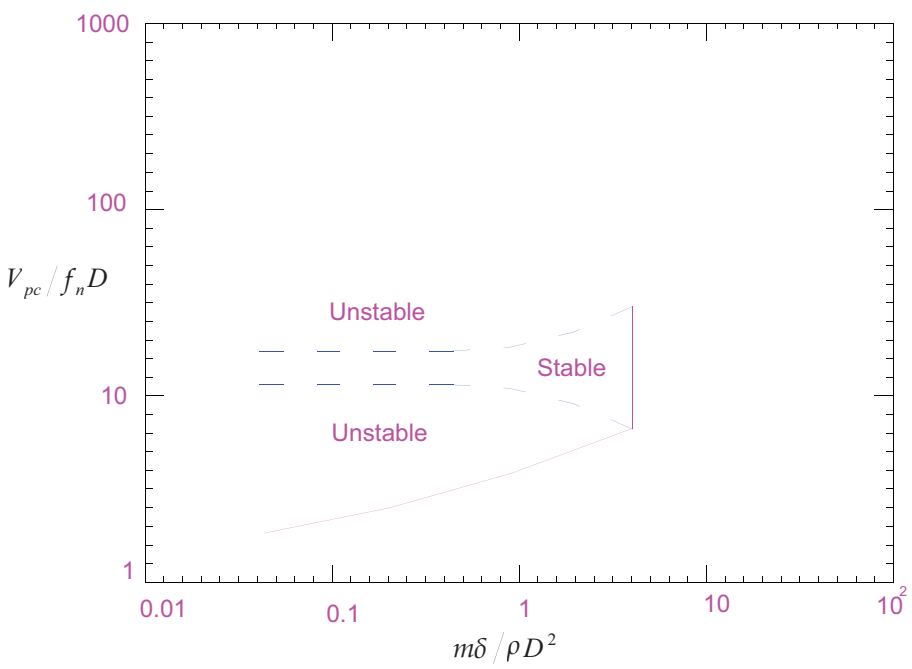

- - -Theoretical solution showing multiple instability boundaries

Practical stability boundary

Fig. 4. Theoretical stability for fluid-elastic instability predicted by (Chen, 1983), for a row of cylinders with $\mathrm{P} / \mathrm{D}=1.33$.

\subsubsection{Semi-analytical model}

Out of many semi analytical models, Figure 5 shows theoretical stability boundary for fluidelastic instability obtained by (Lever \& Weaver, 1986).

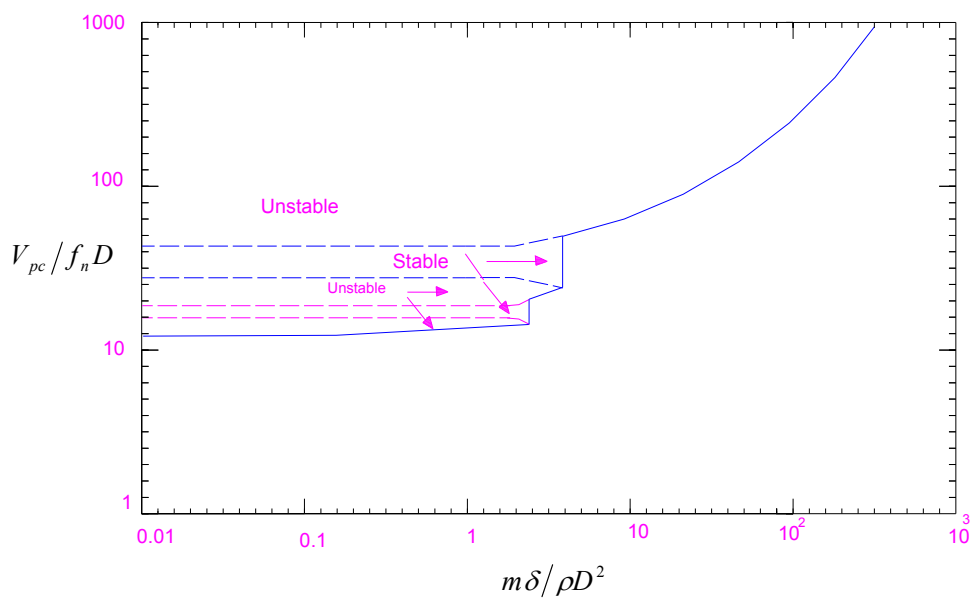

- - Theoretical solution showing multiple instability boundaries

Practical stability boundary

Fig. 5. Theoretical stability boundary for fluid-elastic instability obtained by (Lever \& Weaver, 1986) for single flexible cylinder in a parallel triangular array with $P / D=1.375$. 


\subsubsection{Quasi-steady model}

(Price, 1995) remarks that Fung and Blevins have concluded that quasi-steady fluid dynamics is valid provided $\frac{V}{f_{n} D} \geq 10$; however, experiments by Price, Paidoussis and Sychterz and others suggest that for closely spaced bodies the restriction on the use of quasisteady fluid dynamics is much more severe than that suggested by Fung or Blevins. (Gross, 1975) carried out first quasi-steady analysis of cylinder arrays subjected to cross-flow concluding that instability in cylinder arrays is due to two distinct mechanisms: negative damping and stiffness controlled instability.

\subsubsection{Computational fluid dynamic (CFD) models}

The CFD solutions applicable to fluid-elastic instability and other problem areas of flowinduced vibrations are increasing. These include (Marn and Catton, 1991) and (Planchard \& Thomas, 1993).

\subsubsection{Non-linear models}

The first non-linear model was given by (Roberts, 1962, 1966), who employed Krylov and Bogoliubov method (Minorsky, 1947) of averaging to solve the non-linear equations. Twomotivating forces have been remarked by (Price, 1995) for non-linear analyses. Firstly because of manufacturing tolerances and thermal constraints, there are likely to be small clearances between heat exchanger tubes and intermediate supports. Hence, large lengths of unsupported tubes, having very low natural frequencies. These low-frequencies may suffer from fluid-elastic instability at relatively low $V_{p c}$. A second and more academic motivating force for these non-linear analysis has been to investigate the possibility of Choatic behavior of tube motion.

\subsubsection{Recent researches in fluid-elastic instability}

A summary of some recent efforts on the analysis of fluid-elastic instability in heat exchanger and steam generator tube bundles is given in Table 4.

\begin{tabular}{|l|l|l|l|l|l|l|}
\hline Researchers & $\begin{array}{c}\text { Flow } \\
\text { (phase) }\end{array}$ & $\begin{array}{c}\text { Analysis } \\
\text { type }\end{array}$ & Frequency & Span type & Model type & Remarks \\
\hline $\begin{array}{l}\text { (Hassan } \\
\text { et al., 2011) }\end{array}$ & $\begin{array}{l}\text { Single } \\
\text { phase } \\
\text { Simulation } \\
\text { linear/ } \\
\text { non-linear })\end{array}$ & $\begin{array}{l}\text { Up to } \\
\text { 90Hz } \\
\text { approx. }\end{array}$ & $\begin{array}{l}\text { Loosely } \\
\text { supported } \\
\text { multispan }\end{array}$ & $\begin{array}{l}\text { Tube } \\
\text { supports } \\
\text { with several } \\
\text { time } \\
\text { interaction } \\
\text { fluid force } \\
\text { parameters } \\
\text { model }\end{array}$ & $\begin{array}{l}\text { Impact Force } \\
\text { Contact rates } \\
\text { Normal wave } \\
\text { rate } \\
\text { considered. }\end{array}$ \\
\hline
\end{tabular}




\begin{tabular}{|c|c|c|c|c|c|c|}
\hline Researchers & $\begin{array}{l}\text { Flow } \\
\text { (phase) }\end{array}$ & $\begin{array}{c}\text { Analysis } \\
\text { type }\end{array}$ & Frequency & Span type & Model type & Remarks \\
\hline $\begin{array}{l}\text { (Sim \& } \\
\text { Park, 2010) }\end{array}$ & $\begin{array}{l}\text { Two } \\
\text { phase }\end{array}$ & \begin{tabular}{|l} 
Experimental \\
test section \\
consists of \\
flexible and \\
rigid \\
cylinders
\end{tabular} & \begin{tabular}{|l} 
Frequency \\
Range \\
$8.25-12 \mathrm{~Hz}$
\end{tabular} & $\begin{array}{l}\text { Cantilevered } \\
\text { flexible } \\
\text { cylinders }\end{array}$ & $\begin{array}{l}\text { Normal } \\
\text { square tube } \\
\text { bundles }\end{array}$ & $\begin{array}{l}\text { Dimensionless } \\
\text { flow velocity } \\
\text { and mass- } \\
\text { damping } \\
\text { parameter } \\
\text { consideration } \\
\text { s and fluid- } \\
\text { elastic } \\
\text { instability } \\
\text { coefficients } \\
\text { considerations }\end{array}$ \\
\hline $\begin{array}{l}\text { (Ishihara \& } \\
\text { Kitayama, } \\
\text { 2009) }\end{array}$ & $\begin{array}{l}\text { Single } \\
\text { phase }\end{array}$ & Experimental & & $\begin{array}{l}\text { Tube banks } \\
\text { such as } \\
\text { boilers and } \\
\text { heat } \\
\text { exchangers in } \\
\text { power plant }\end{array}$ & Experimental & $\begin{array}{l}\text { Onset of } \\
\text { fluid-elastic } \\
\text { instability } \\
\text { and geometry } \\
\text { relationship } \\
\text { considerations }\end{array}$ \\
\hline $\begin{array}{l}\text { (Mitra } \\
\text { et al., 2009) }\end{array}$ & $\begin{array}{l}\text { Single \& } \\
\text { two } \\
\text { phase } \\
\text { (Air- } \\
\text { water \& } \\
\text { air-steam } \\
\text { flow) }\end{array}$ & Experimental & $\begin{array}{l}\text { Frequency } \\
\text { range } \\
7.6-13.74 \\
\mathrm{~Hz}\end{array}$ & & $\begin{array}{l}\text { Fully flexible } \\
\text { tube arrays } \\
\text { and single } \\
\text { flexible tube } \\
\text { (Normal } \\
\text { square } \\
\text { array) }\end{array}$ & $\begin{array}{l}\text { Displacement } \\
\text { and damping } \\
\text { mechanisms } \\
\text { Critical flow } \\
\text { velocity was } \\
\text { found } \\
\text { proportional } \\
\text { to tube arrays }\end{array}$ \\
\hline $\begin{array}{l}\text { (Mahon \& } \\
\text { Meskell, } \\
\text { 2009) }\end{array}$ & $\begin{array}{l}\text { Single } \\
\text { phase }\end{array}$ & $\begin{array}{c}\text { Experimental } \\
P / D\end{array}$ & $\begin{array}{l}\text { Excitation } \\
\text { frequency } \\
6.62 \mathrm{~Hz}\end{array}$ & $\begin{array}{l}\text { Second array } \\
\text { flexible tube } \\
\text { with electro- } \\
\text { magnetic } \\
\text { damper }\end{array}$ & $\begin{array}{l}\text { Normal } \\
\text { Triangular }\end{array}$ & $\begin{array}{l}\text { Time delay } \\
\text { considerations }\end{array}$ \\
\hline $\begin{array}{l}\text { (Hassan \& } \\
\text { Hayder, } \\
2008)\end{array}$ & $\begin{array}{l}\text { Single } \\
\text { phase }\end{array}$ & $\begin{array}{l}\text { Modeling } \\
\text { and } \\
\text { simulation } \\
\text { (Linear/ } \\
\text { Non-linear) }\end{array}$ & $\begin{array}{l}\mathrm{Up} \text { to } \\
60 \mathrm{~Hz}\end{array}$ & & $\begin{array}{l}\text { Time } \\
\text { domain } \\
\text { modeling of } \\
\text { tube forces }\end{array}$ & $\begin{array}{l}\text { Critical } \\
\text { velocity } \\
\text { predictions } \\
\text { dependent } \\
\text { upon i.e. } \\
\text { sensitive to } \\
\text { both gap size } \\
\text { and } \\
\text { turbulence } \\
\text { level }\end{array}$ \\
\hline $\begin{array}{l}\text { (Chung \& } \\
\text { Chu, 2006) }\end{array}$ & $\begin{array}{l}\text { Two } \\
\text { phase } \\
\text { Void } \\
\text { Fraction } \\
10-95 \%\end{array}$ & $\begin{array}{l}\text { Experimental } \\
P / D=1.633 \\
100 \mathrm{~m}^{3} / \mathrm{hr} \\
50 \mathrm{~m} \text { Water } \\
\text { Head }\end{array}$ & \begin{tabular}{|l} 
Strouhal \\
number \\
$0.15-0.19$
\end{tabular} & $\begin{array}{l}\text { Cantilevered } \\
\text { straight tube } \\
\text { bundles }\end{array}$ & Experimental & $\begin{array}{l}\text { Hydro } \\
\text { dynamic } \\
\text { coupling } \\
\text { effects } \\
\text { consideration }\end{array}$ \\
\hline
\end{tabular}




\begin{tabular}{|l|l|l|l|l|l|l|}
\hline Researchers & $\begin{array}{c}\text { Flow } \\
\text { (phase) }\end{array}$ & $\begin{array}{c}\text { Analysis } \\
\text { type }\end{array}$ & Frequency & Span type & Model type & Remarks \\
\hline $\begin{array}{l}\text { (Mureithi } \\
\text { et al., 2005). }\end{array}$ & $\begin{array}{l}\text { Single } \\
\text { phase } \\
\text { damperimental } \\
\text { damping }\end{array}$ & $\begin{array}{l}\text { Expind tunnel } \\
\text { partially } \\
\text { fixed flexible } \\
\text { array } \\
P / D=1.633\end{array}$ & $18.74 \mathrm{~Hz}$ & $\begin{array}{l}\text { Preferentially } \\
\text { flexible }\end{array}$ & $\begin{array}{l}\text { Rotated } \\
\text { triangular } \\
\text { array }\end{array}$ & $\begin{array}{l}\text { Investigation } \\
\text { of stability } \\
\text { behavior and } \\
\text { AVB's } \\
\text { considerations }\end{array}$ \\
\hline
\end{tabular}

Table 4. A summary of recent fluid-elastic instability research

\subsection{Vorticity induced instability}

Flow across a tube produces a series of vortices in the downstream wake formed as the flow separates alternatively from the opposite sides of the tube. This shedding of vortices produces alternating forces, which occur more frequently as the velocity of flow increases. For a single cylinder, frequency of vortex shedding $f_{v s}$ is given below by a dimensionless Strouhal number $S$.

$$
f_{v s}=\frac{S V}{D}
$$

where $V$ is the flow velocity and $D$ is the tube diameter. For a single cylinder, the vortex shedding Strouhal number is a constant with a value of about 0.2 (Chenoweth, 1993). Vortex shedding occurs for the range of Reynolds number $100<\mathrm{R}_{\mathrm{e}}<5 \times 10^{5}$ and $>2 \times 10^{6}$ whereas it dies out in-between. The gap is due to a shift of the flow separation point in vortices in the intermediate transcritical Reynolds number range. Vortex shedding can excite tube vibration when it matches with the natural frequency of the tubes. For tube banks with vortex shedding, Strouhal number is not constant, but varies with the arrangement and spacing of tubes, typical values for in-line and staggered tube bundle geometries are given in (Karaman, 1912, Lienhard, 1966). Strouhal numbers for in-line tube banks are given in Figure 6.

The vortex shedding frequency can become locked-in to the natural frequency of a vibrating tube even when flow velocity is increased (Blevins, 1977). Earlier on, the mechanism of vortex shedding has been investigated by a number of researchers. These include Sipvack (Sipvack, 1946) and, Thomas and Kraus (Thomas \& Kraus, 1964) who investigated the vortex shedding of two cylinders arranged parallel and perpendicular to flow direction respectively. Grotz and Arnold (Groth \& Arnold, 1956) measured for the first time systematically the vortex shedding frequencies in in-line tube bank for various tube spacing ratios.

The cause of vorticity excitation has been disputed in literature (Owen, 1965), but recent studies of (Weaver, 1993) and, (Oengoren \& Ziada, 1993) have confirmed its cause of existence as periodic vortex formation. Vorticity shedding can cause tube resonance in liquid flow or acoustic resonance of the tube bundles or acoustic resonance of the tube bundles' containers in gas flows (Oengoren \& Ziada, 1995). (Chen, 1990), (Zaida \& Oengoren, 1992) and (Weaver, 1993) have summarized the recent research efforts targeted at improvement in Strouhal number charts for vortex shedding and acoustic resonance for inline tube bundles. 


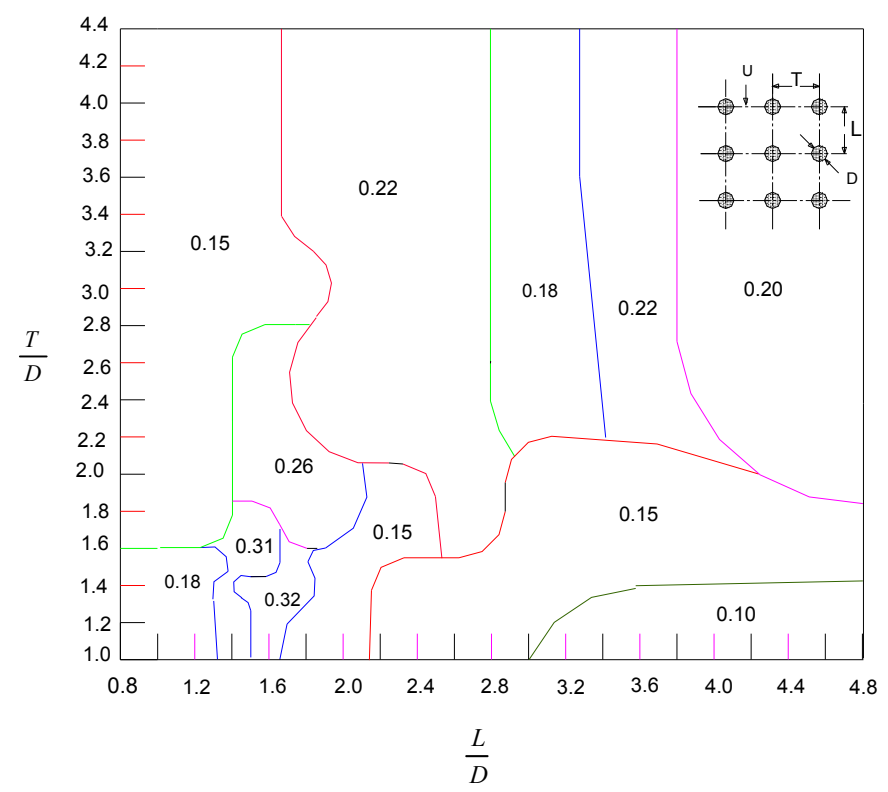

Fig. 6. Strouhal numbers for in-line tube banks (Karaman, 1912).

(Oengoren and Ziada, 1992) have investigated the coupling between the acoustic mode and vortex shedding, which may occur near the condition of frequency coincidence. They have investigated the system response both in the absence and in the presence of a splitter plate, installed at the mid-height of the bundle to double the acoustic resonance frequencies and therefore double the Reynolds number at which frequency coincidence occurs. They have also investigated the effect of row number on vortex shedding and have carried out flow visualization in Reynolds number range of $\leq 355000$. Figure 7 is a typical example of the mechanism of vortex shedding from the tubes of the first two rows displaying a time series of symmetric and anti-symmetric patterns (Oengoren \& Ziada, 1993).

(Liang et al., 2009) has addressed numerically the effect of tube spacing on vortex shedding characteristics of laminar flow past an inline tube arrays. The study employs a six row inline tube bank for eight pitch to diameter $(P / D)$ ratios with Navier-Strokes continuity equation based unstructured code (validated for the case of flow past two tandem cylinders) (Axisa \& Izquierdo, 1992) . A critical spacing range between 3.0 and 3.6 is identified at which mean drag as well as rms lift and drag coefficients for last three cylinders attain maximum values. Also at critical spacing, there is $180^{\circ}$ phase difference in the shedding cycle between successive cylinders and the vortices travel a distance twice the tube spacing within one period of shedding.

(Williamson \& Govardhan, 2008) have reviewed and summarized the fundamental results and discoveries related to vortex induced vibrations with particular emphasis to vortex dynamics and energy transfer which give rise to the mode of vibrations. The importance of mass and damping and the concept of "critical mass", "effective elasticity" and the relationship between force and vorticity. With reference to critical mass, it is concluded that 
as the structural mass decreases, so the regime of velocity (non-dimensional) over which there is large amplitude of vibrations increases. The synchronizing regime become infinitely wide not simply when mass become zero but when a mass falls below special critical value when the numerical value depends upon the vibrating body shape.

(a)
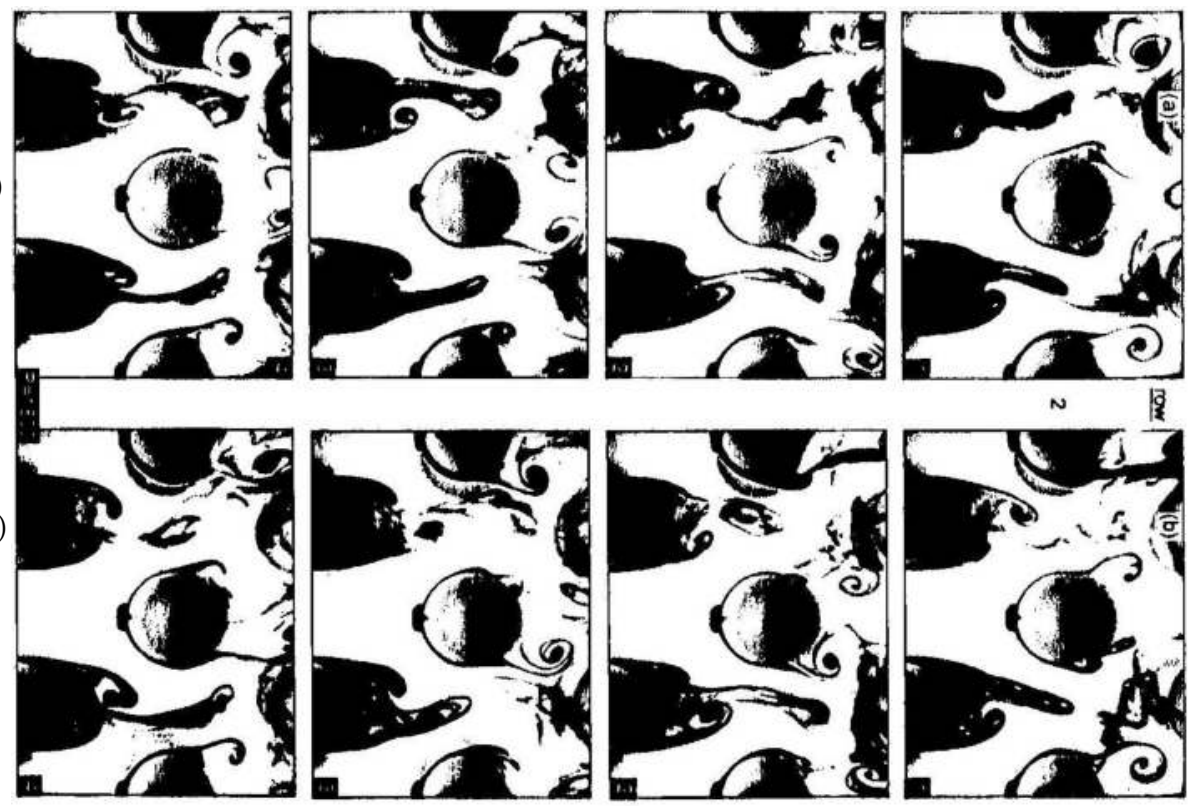

Fig. 7. Time sequence of the two transient modes of vortex shedding, (a) symmetric and (b) anti-symmetric, behind the first two rows of the intermediate spacing array (Leinhard, 1966).

(Williamson \& Govardhan, 2000) present a large data set for the low branch frequency $f_{\text {lower }}^{*}$ plotted versus $m^{*}$ (mass ratio) yielding a good collapse of data on to single curve base equation 7.

$$
f_{\text {lower }}=\sqrt{\frac{m^{*}+1}{m^{*}-0.54}}
$$

This equation provides a practical and simple means to calculate the frequency attained by vortex induced vibrations. The critical mass ratio is given by

$$
m_{\text {crit }}^{*}=0.54 \pm 0.002
$$

Below which the lower branch of response can never be attained. With respect to combine mass-damping parameter's capability to reasonably collapse peak amplitude data in Griffins plot, a number of parameters like stability parameter, Scrutom number and combined response parameter termed as Skop-Griffins parameter given by $\left(\mathrm{S}_{\mathrm{G}}\right)$ :

$$
S_{G}=2 \pi^{3} S^{2}\left(m^{*}\right)
$$


Where $S$ stands for single vortices and $S_{c}$ is the Scruton number.

(Hamakawa \& Matsue, 2008) focused on relation between vortex shedding and acoustic resonance in a model (boiler plant) for tube banks to clarify the interactive characteristics of vortex shedding and acoustic resonance. Periodic velocity fluctuation due to vortex shedding was noticed inside the tube banks at the Reynolds number (1100-10000) without acoustic resonance and natural vortex shedding frequency of low gap velocities. Kumar et al., 2008 in their review stated that controlling or suppressing vortex induced vibrations is of importance in practical applications where active or passive control could be applied.

(Paidoussis, 2006) specially addressed real life experiences in vortex induced vibrations and concludes with this mechanism in addition of other already clarified mechanisms of flow induced vibrations. Vortex induced vibrations of ICI nozzles and guide tubes in PWR for ICI thimble guiding into the core of the reactor to monitor reactivity may witness breakage of ICI nozzles resulting in strange noises experience in the reactor. Analysis of shedding frequencies confirmed the vortex induced vibrations to be the culprit partially due to the large values of varying lift coefficients and partially due to lock-in.

(Hamakawa \& Fukano, 2006) also focused vortex shedding in relation with the acoustic resonance in staggered tube banks and observe three Strouhal number $(0.29,0.22$ and 0.19$)$. In cases with no resonance inside tube banks, the last rows of tube banks and in both regimes respectively. The vortices of 0.29 and 0.22 components alternatively irregularly originated.

(Pettigrew \& Taylor, 2003) discussed and overviewed procedures and recommended design guidelines for periodic wave shedding in addition to other flow induced vibration considerations for shell and tube heat exchangers. It concludes that the fluctuating forces due to periodic wave shedding depends on the number of considerations like geometric configuration of tube bundles, its location, Reynolds number, turbulence, density of fluid and pitch to diameter $P / D$ ratio.

\subsection{Turbulence excitation}

Extremely turbulent flow of the shell-side fluid contains a wide spectrum of frequencies distributed around a central dominant frequency, which increases as the cross-flow velocity increases. This turbulence buffets the tubes, which extract energy from the turbulence at their natural frequency from the spectrum of frequencies present. When the dominant frequency for the turbulent buffeting matches the natural frequency, a considerable transfer of energy is possible leading to significant vibration amplitudes (Chenoweth, 1993). Turbulent flow is characterized by random fluctuation in the fluid velocity and by intense mixing of the fluid. Nuclear fuel bundles and pressurized water reactor (PWR) steam generators are existing examples (Hassan \& Ibrahim, 1997).

Turbulence is by nature three-dimensional (Au-Yang, 2000). Large-Eddy Simulation, (LES) incorporated in three-dimensional computer codes has become one of the promising techniques to estimate flow turbulence. (Hassan \& Ibrahim, 1997) \& (Davis \& Hassan, 1993) have carried out Large Eddy Simulation for turbulence prediction in two-and threedimensional flows. The primary concern in turbulence measurements is how the energy spectrum or the power spectral density (PSD) of the eddies are distributed. The PSD of the 
velocity profile $\mathrm{E}(\mathrm{n})$ is numerically equal to the square of the Fourier Transform of $U^{\prime}(t)$, and is defined to be (Hassan \& Ibrahim, 1997).

$$
\overline{U^{\prime 2}}=\int_{-\infty}^{+\infty} E(n) d n
$$

where $E(n)$ is the sum of power at positive and negative frequency $n$.

$$
E(n)=\frac{4 \pi^{2}|a(n)|^{2}}{T}
$$

where $T$ is the time period over which integration is performed, and $a(n)$ is the Fourier Transform coefficient.

An important parameter of flow turbulence is the correlation function. The Lagrangian (temporal) auto-correlation over a time $\mathrm{T}$ gives the length of time (past history) that is related to a given event (Hassan \& Ibrahim, 1997).

$$
\begin{gathered}
\text { (Non-dimensional) } \mathrm{R}(\tau)=\frac{\overline{\mathrm{U}^{\prime}(t) U^{\prime}(t+\tau)}}{\overline{U^{\prime}(t) U^{\prime}(t)}} \\
\text { (Dimensional) } \mathrm{R}(\tau)=\lim _{\lim \longrightarrow \infty} \frac{1}{T} \int_{t=0}^{t=T} U^{\prime}(t) U^{\prime}(t+\tau) d t
\end{gathered}
$$

Physically $R(\tau)$ represents the average of the product of fluctuating velocity $U^{\prime}$ values at a given time and at a time $\tau$ later. $R(\tau)$ gives information about whether and for how long the instantaneous value of $U^{\prime}$ depends on its previous values. Cross-correlation curves can also be obtained as a function of the time delay to give the correlation between the velocities at consecutive separated location points (Owen, 1965).

$$
R_{12}(\tau)=\frac{1}{T} \int_{t=0}^{t=T} U_{1}^{\prime}(t) U_{2}^{\prime}(t+\tau) d t
$$

where $R_{12}$ gives the cross-correlation of the U-velocity component at 1 - and 2- point locations.

Recently (Au-Yang, 2000) has reviewed the acceptance integral method to estimate the random vibration, Root Mean Square (RMS) of structures subjected to turbulent flow (random forcing function). The acceptance integral is given by:

$$
J_{\alpha \beta}(\omega)=\frac{1}{\ell} \int_{0}^{\ell} \int_{0}^{\ell} \phi_{\alpha}\left(x^{\prime}\right)\left[S_{p}\left(x^{\prime}, x^{\prime \prime}, \omega\right) / S_{p}\left(x^{\prime}, \omega\right)\right] \phi_{\beta}\left(x^{\prime \prime}\right) d x^{\prime} d x^{\prime \prime}
$$

When $\alpha=\beta, \mathrm{J}_{\alpha \alpha}$ is known as joint acceptance

where 
$J_{\alpha \alpha}=\quad$ Joint acceptance for $\alpha_{t h}$ mode

$J_{\alpha \beta} \quad=\quad$ Cross-acceptance

$\ell \quad=\quad$ Surface of 2-D structure of length of 1-D structure

$x \quad=\quad$ Position vector

$S_{p} \quad=\quad$ Double sided pressure power spectral density.

$\phi_{\alpha} \quad=\quad$ Mode shape function

$\phi_{\beta} \quad=\quad$ Mode shape function

$\omega \quad=\quad$ Frequency

$\alpha, \beta=$ Modal indices

Yang obtained closed form solutions for the joint acceptances for two special cases of springsupported and simply-supported beams. A review of turbulence in two-phase is presented by (Khushnood et al., 2003).

(Endres \& Moller, 2009) present the experimental analysis of disturbance propagation with a fixed frequency against cross flow and its effect on velocity fluctuations inside the bank. It is concluded that continuous wavelet transforms of the signals. Figure 8 indicates the disturbance frequency to be showing steady behavior. Generally designing for enhanced heat exchange ratios in thermal equipments ignores the structural effects caused by turbulent flow.
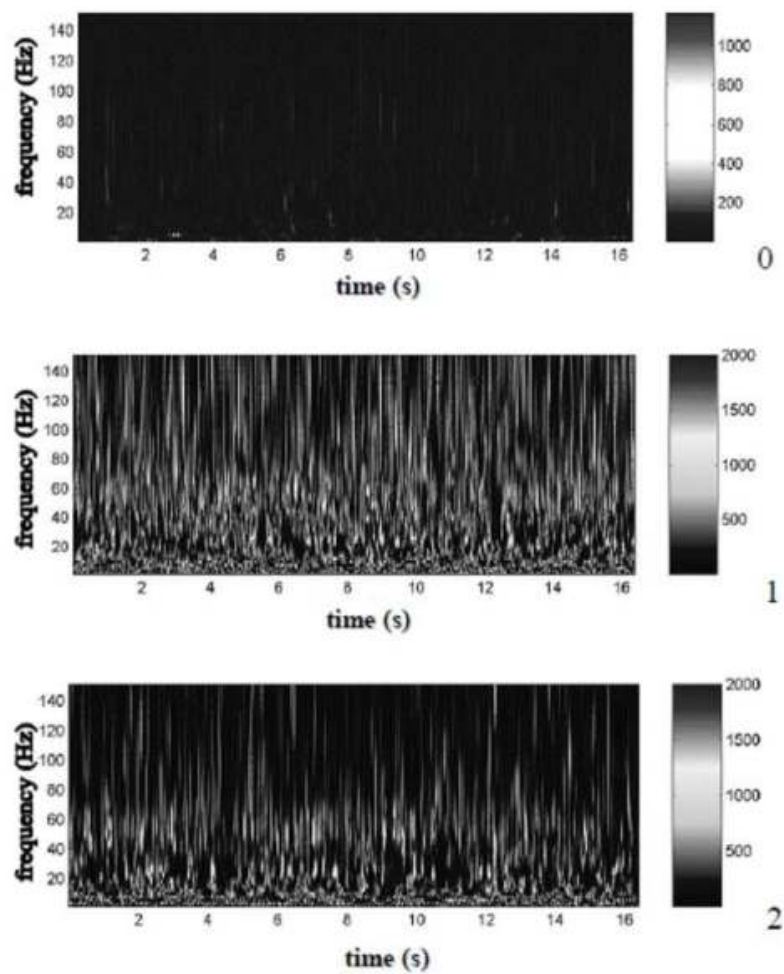

Fig. 8. Continuous wavelet transforms of the signals at locations 0,1 and 2 . Tube bank with $\mathrm{P} / \mathrm{D}=1.26$, vortex generator $\# 2, \operatorname{Re}_{\mathrm{G}}=6.46 \times 10^{4}$ (Endres \& Möller, 2009). 
(Pascal-Ribot and Blanchet, 2007) proposed a formulation to collapse the dimensionless spectra of buffeting forces in a single characteristic curve and gives edge to the formulation over previously normalized models in terms of collapse of data.

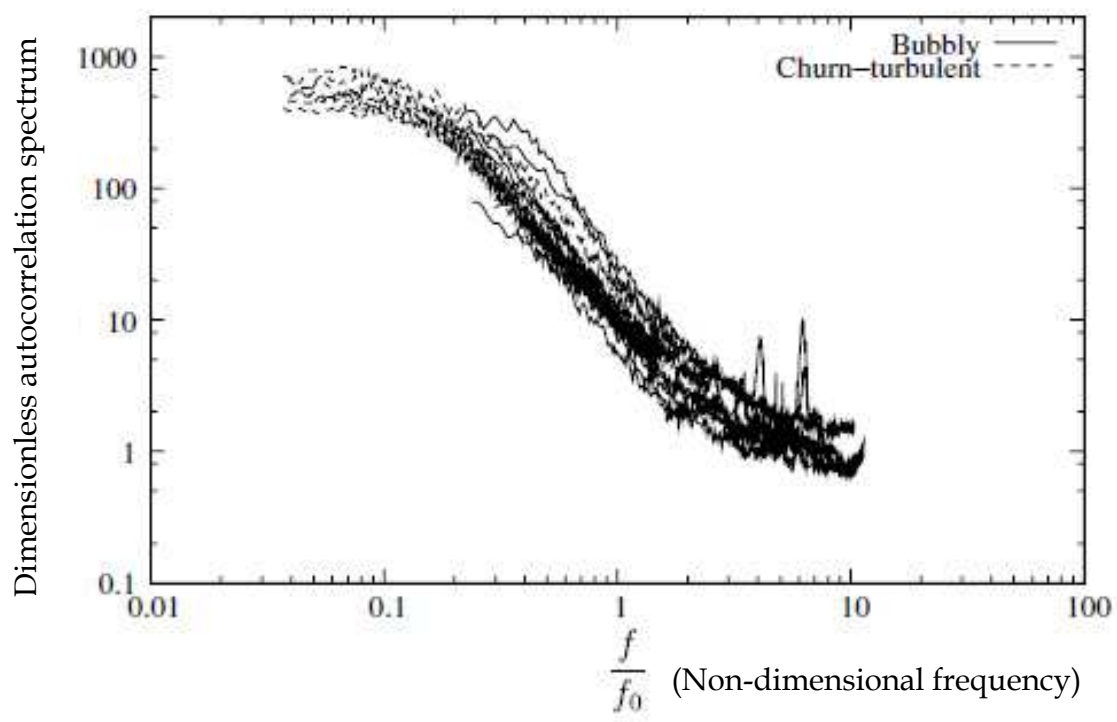

Fig. 9. Dimensionless reference equivalent spectra (Barrington, 1973)

Figure 9 shows the dimensionless spectra calculated with equations $15 \& 16$ respectively.

$$
\begin{gathered}
P_{o}=k \rho_{1} g \sqrt{\frac{\sigma}{\Delta \rho g}}[\alpha(1-\alpha)]^{2} \\
P_{0}=k \rho_{1} g \sqrt{\frac{\sigma}{\Delta \rho g}}\left[\alpha_{c t}\left(1-\alpha_{c t}\right)\right]^{2}: \alpha_{c t}=0.4
\end{gathered}
$$

Where $a$ is the void fraction.

(Wang et al., 2006) concludes the physically realistic solutions for turbulent flow in a staggered tube banks can be realized by FLUENT (with 2-D Reynolds stress model).

Figure 10 shows the consistency of turbulence intensity contours obtained through standard wall function approach and non-equilibrium wall function approach whereas near-wall treatment model and near -wall turbulence model predicts much higher results (Wang, et al., 2006). 


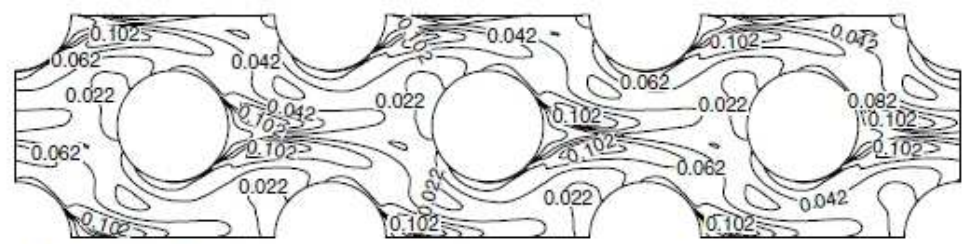

a) Standard wall function

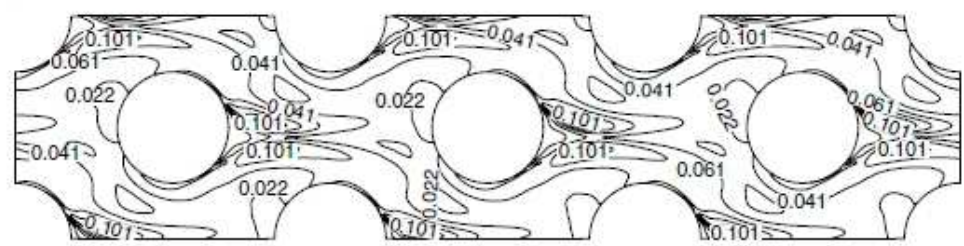

b) Non-equilibrium wall function

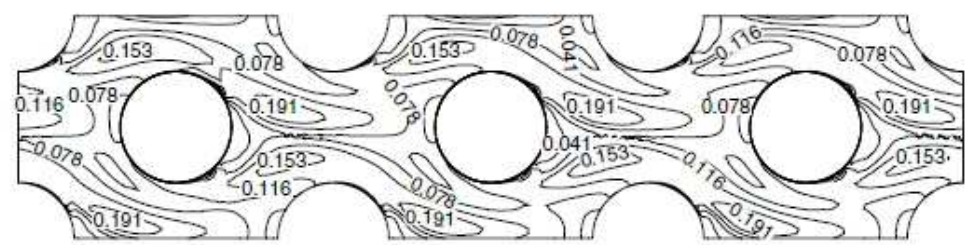

c) Near wall treatment

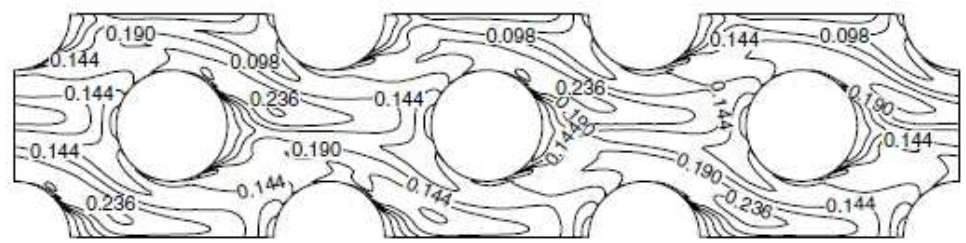

d) Near wall turbulence model

Fig. 10. Turbulence intensity contours (Barrington, 1973)

\subsection{Acoustic resonance}

Acoustic vibration occurs only when the shell-side fluid is a vapor or a gas. The characteristic frequency of acoustic vibration in a heat exchanger depends on some characteristic length, usually the shell diameter and the velocity of sound in shell-side fluid, $U_{\text {sound }}$. The acoustic frequency (Chenoweth, 1993) can be predicted by the following equation.

$$
f_{a}=\frac{m U_{\text {sound }}}{2 d}
$$

where $m$ is the mode number (a dimensionless integer), and $d$ is the shell diameter. The lowest acoustic frequency is achieved when $m=1$ and the characteristic length is the shell diameter. The acoustic frequencies of an exchanger can be excited by either vortex shedding or turbulent buffeting (Chenoweth, 1993). (Barrington, 1973) indicated that so 
long as the exciting frequencies are within $20 \%$ of an acoustic frequency, a loud sound may be produced. Acoustic vibration becomes destructive when it is in resonance with some component of exchanger. The acoustic frequencies of shell can be changed by inserting a detuning plate parallel to the direction of cross-flow to alter the characteristic length (Chenoweth, 1993). There are a number of published acoustic vibration criteria to predict strong acoustic vibration within a tube bank, including (Eisinger et al., 1994), (Groth \& Arnold, 1956), (Chen, 1968), (Fitzpatrick, 1986), (Ziada et al.,) and Blevins (Blevins, 1990 ).

(Hanson \& Ziada, 2011) have investigated the effects of acoustic resonance on the dynamic lift force acting on the central tube. Two effects of resonant sound field includes generation of "sound induced" dynamic lift because of resonant acoustic pressure distribution on the tube surface and synchronization of vorticity shedding. Sound enhancements coefficients and sound induced lift force development is carried through numerical solution. (Hanson et al., 2009) investigated aeroacoustic response of two side-by-side cylinders against cross flow. It is concluded that acoustic resonance synchronizes vortex shedding and eliminates bistable flow phenomenon. Vortex shedding is noticed a particular strouhal number which excites acoustic resonance. Figure 11 and figure 12 gives the pressure spectra for two side-by-side cylinders and aeroacoustic response of two side-by-side cylinders.

(Eisinger \& Sullivan, 2007) considers strong acoustic resonance with acoustic pressure reading $165 \mathrm{~dB}$ for package boiler at near full load, suppression of resonance (lower frequency) through baffle covering with downstream section and the development of another resonance (higher frequency) in the unbaffled upstream section.

(Feenstra et al., 2006) carried out experimental investigation of the effects of width of test section for measuring the acoustic resonance with a small pitch rates staggered tubes. The conclusion was that the maximum acoustic pressure versus input energy parameter of Blevins and Bressler is not a reliable preditor and it over predicts.

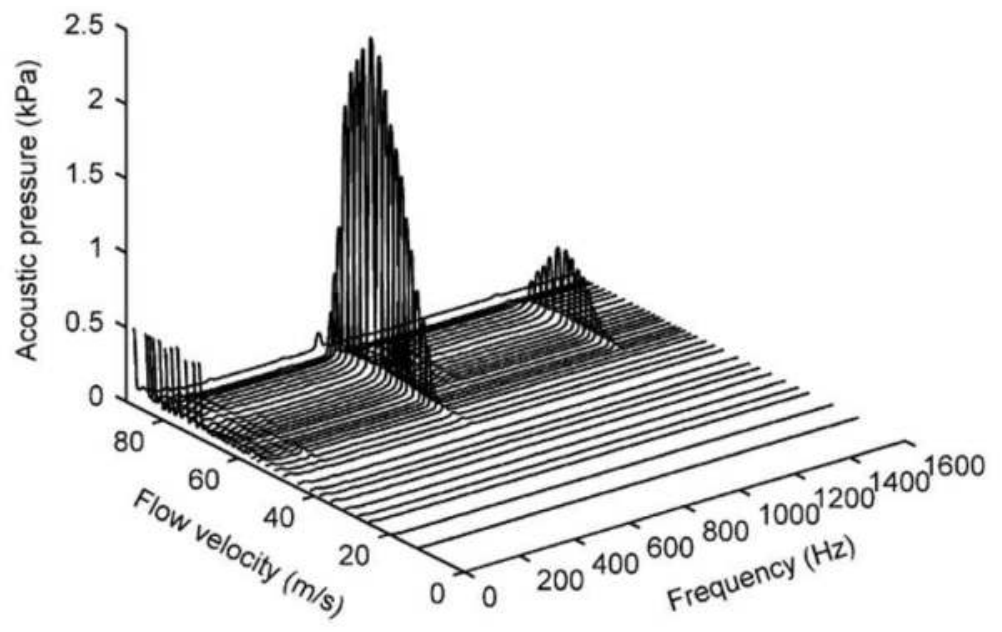

Fig. 11. Pressure spectra for the two side-by-side cylinders for T/D=1.25 (Hanson, et al., 2011) 


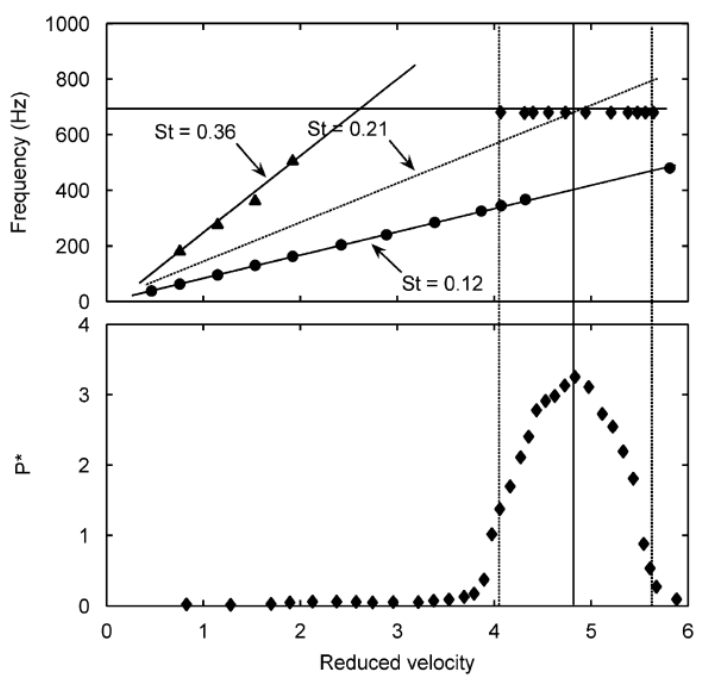

Fig. 12. Aeroacoustic response of the two side-by-side cylinders with $\mathrm{T} / \mathrm{D}=1.25$ and $\mathrm{D}=21.8$ $\mathrm{mm}$ (Hanson, et al., 2011) (Eisinger \& Sullivan, 2005) test results concluded that wide test sects gives the maximum acoustic pressure (lower acoustic mode) at $\mathrm{P}=53.4 \mathrm{MPa}$ which is 4.27 times greater than predicted by Blevins and Bressler.

\section{Natural frequencies of tube vibration}

In flow-induced vibration design of heat exchanger tube bundles, resonant conditions must be suppressed by ensuring separation of natural frequencies of the tubes and exciting frequencies (Shin \& Wambsganss,1975). A number of techniques are available for computing natural frequencies of straight, curved, single and multiple span tubes. These tubes may be subjected to varying end conditions. Loose baffles act like "kinfe-edged rings" supports (Timoshenko, 1955) . Tubes are rigidly fastened to the tube sheet and supported at intermediate points along their lengths by baffles or support plates. Some tubes in the centre may be supported by every baffle, whereas tubes that pass thorough baffle window may be supported by every second and third baffle. Table 5 (MacDuff \& Feglar, 1957, Kissel, 1977) gives some of the formulas/techniques for estimating the natural frequencies of straight-and curved-or U-tubes.

\subsection{Variables affecting tube natural frequencies}

The tube natural frequencies are affected by tube-to-baffle hole clearance, axial stress, fins, span length, span shape (straight, U-tube), support type, temperature and tube vibration (Chenoweth, 1976, Elliot \& Park, 1973, Pettigrew et al., 1986, Simpson et al., 1974, Tanaka \& Takahara, 1981, TEMA Standards, $8^{\text {th }}$ edition). At about one tenth of TEMA allowable clearance, the frequency is about $7 \%$ higher than that predicted for simple supports. For most exchangers, tube-to-hole clearance is not a significant parameter for controlling natural frequencies, but it may be important in damping and tube wear (Chenoweth, 1993). Due to manufacturing procedures, the tubes may be under a tension or compression axial loading. (Kissel, 1972) found a variation in natural frequency due to axial loading in a typical 
exchanger as much as $\pm 40 \%$. The natural frequency varies as reciprocal of the span length squared (unsupported span). For finned tubes, effective diameter for the outside diameter should be used to find the area moment of inertia for natural frequency calculation (Chenoweth, 1993). Currently, software by TEMA (FIV) (TEMA Standards, 8th edition) is capable of predicting the natural frequencies.

\begin{tabular}{|c|c|}
\hline Formula/ Procedure & Conditions \\
\hline$f_{n}=\left(\frac{1}{2 \pi}\right) \frac{\lambda_{n}}{l^{2}}\left(\frac{E I}{m}\right)^{1 / 2}$ (Jones, 1970) & $\begin{array}{l}\text { Straight beams / single span } \\
n \text { is the mode number and } \lambda_{n} \text { is a frequency } \\
\text { factor which depends upon the end conditions }\end{array}$ \\
\hline$f_{n}=\frac{1}{2 \pi} \lambda_{n}\left(\frac{1}{R \alpha}\right)\left(\frac{E I}{m}\right)^{1 / 2}$ (Archer, 1960) & $\begin{array}{l}\text { Curved beams / single span } \\
\lambda_{n} \text { is a frequency factor } \\
R \text { is the radius of curvature and } \alpha \text { is the } \\
\text { subtended angle }\end{array}$ \\
\hline $\begin{array}{l}f_{n}=59.55 \frac{C_{u}}{L^{2}}\left(\frac{E I}{M_{e}}\right)^{0.5} \\
\text { (TEMA, 6th Edition, 1978) }\end{array}$ & $\begin{array}{l}\text { U-tube curved } \\
C_{u} \text { is the first mode U-tube constant }\end{array}$ \\
\hline $\begin{array}{l}\text { Experimental/ computer program } \\
f_{n}=\frac{\left(\beta_{n} L\right)^{2}}{2 \pi L^{2}} \sqrt{\frac{E I g}{W}} \\
\text { (Lowery \& Moretti, 1975) }\end{array}$ & $\begin{array}{l}\text { Straight/multiple, free-free spans }(1-5 \text { span } \\
\text { tests); idealized support conditions, }\left(\beta_{n} L\right)^{2} \text { is } \\
\text { eigen value }\end{array}$ \\
\hline $\begin{array}{l}\text { FEM in-plane and out of plane } \\
\text { Experimental/ analytical } \\
\text { (Elliott \& Pick, 1973) }\end{array}$ & Straight/curved \\
\hline $\begin{array}{l}\text { Beams immersed in liquids, air, kerosene, } \\
\text { and oil (Jones, 1970) }\end{array}$ & Straight/simply supported/clamped \\
\hline $\begin{array}{l}\text { Out of plane: } \\
f_{n}=3.13 \frac{\lambda_{n}}{R^{2}} \sqrt{\frac{C}{\gamma A}} \quad \lambda_{n}=\frac{n\left(n^{2}-1\right)}{\sqrt{1+k n^{2}}} \\
\text { (Ojalvo \& Newman, 1964) }\end{array}$ & $\begin{array}{l}\text { Clamped ring segments } \\
n \text { is mode number; } k \text { is bending stiffness } \\
\gamma \text { is specific weight; } C \text { is the torsional stiffness. } \\
A \text { is cross-sectional area }\end{array}$ \\
\hline $\begin{array}{l}\text { Graphical in-plane and out of plane } \\
\text { (Chen \& Wambsganss, 1974) }\end{array}$ & Straight/curved, single span /multiple span \\
\hline
\end{tabular}




\begin{tabular}{|c|c|}
\hline Formula/ Procedure & Conditions \\
\hline $\begin{array}{l}\text { Analytical/experimental } \\
\text { (Khushnood et al., 2000) }\end{array}$ & $\begin{array}{l}\text { Straight tubes single/multiple spans with } \\
\text { damped/ fixed boundaries, Experimentation on } \\
\text { refinery research exchanger (in-service) }\end{array}$ \\
\hline \multirow{3}{*}{$\begin{array}{l}\text { Plucking and transient decay } \\
\text { (Simpson \& Hartlen, 1974) }\end{array}$} & $\begin{array}{l}\text { Tubes were not fully straightened. } \\
\text { (Slight residual wiggleness) }\end{array}$ \\
\hline & $\begin{array}{l}\text { Wind tunnel determination of fluid-elastic } \\
\text { thresholds }\end{array}$ \\
\hline & Tubes were found sensitive to temperature \\
\hline
\end{tabular}

Table 5. Tube natural frequencies (MacDuff et al., 1957, Kissel, 1977)

\section{Dynamic parameters}

Added mass and damping are known to be dependent on fluid properties (in particular, fluid density and viscosity) as well as functions of component geometry and adjacent boundaries, whether rigid or elastic. Nuclear reactor components are typically immersed in a liquid coolant and are often closely spaced (Wambsganss, et al., 1974).

\subsection{Added mass}

(TEMA, 7th Edition, 1988) defines hydrodynamic mass as an effect which increases the apparent weight of the vibrating body due to the displacement of the shell-side flow resulting from motion of vibrating tubes, the proximity of other tubes within the bundles and relative location of shell-wall. The so-called "virtual mass" for a tube is composed of the mass of the tube, mass of the fluid contained in the tube and the inertia $M^{\prime}$ imposed by the surrounding fluid. This hydrodynamic mass $M^{\prime}$ is a function of the geometry, the density of the fluid, and the size of the tube. In an ideal fluid, it is proportional to the fluid density and to the volume of the tube (Moretti \& Lowry, 1976), and hence may be expressed, per unit length as:

$$
\frac{\mathrm{M}^{\prime}}{\mathrm{L}}=C_{m} \rho \pi r^{2}
$$

where $L$ is the tube length, $r$ the radius of the tube and $\rho$ is the mass per unit volume of the surrounding fluid, $C_{m}$ is called the inertia coefficient which is a function of the geometry, and is discussed by Lamb (Lamb, 1932, 1945). If the moving tube is not infinitely long, the flow is three-dimensional and leads to smaller values of $C_{m}$ (Moretti \& Lowry, 1976). For a vibrating tube in a fluid region bounded by a circular cylinder, Stokes (Endres \& Moller, 2009) has determined hydrodynamic mass per unit length as given by:

$$
m_{h}=C_{m} m_{a}
$$


where $C_{m}=\frac{R^{2}+r^{2}}{R^{2}-r^{2}}, R$ is the outer radius of annulus and, $m_{a}=\rho \pi r^{2}$, where $\rho$ is fluid density, and $r$ is the tube radius.

(Wambsganss, et al., 1974) have published a study on the effect of viscosity on $C_{m}$. Hydrodynamic mass $M^{\prime}$ for a tube submerged in water was determined by measuring its natural frequency, $f_{a}$, in air and, $f_{w}$, in water. Neglecting the density of air compared to water, the following equation may be obtained from beam equation (Moretti \& Lowry, 1976).

$$
\frac{M^{\prime}}{L}=\mu\left[\left(\frac{f_{a}}{f_{w}}\right)^{2}-1\right]
$$

where $\mu$ is the tube mass per unit length. The inertia coefficient, $C_{m}$, can be obtained from Equation 18. Figure 13 gives the results showing the variation of $C_{m}$ with pitch-to-diameter ratios (Wambsganss, et al., 1974).

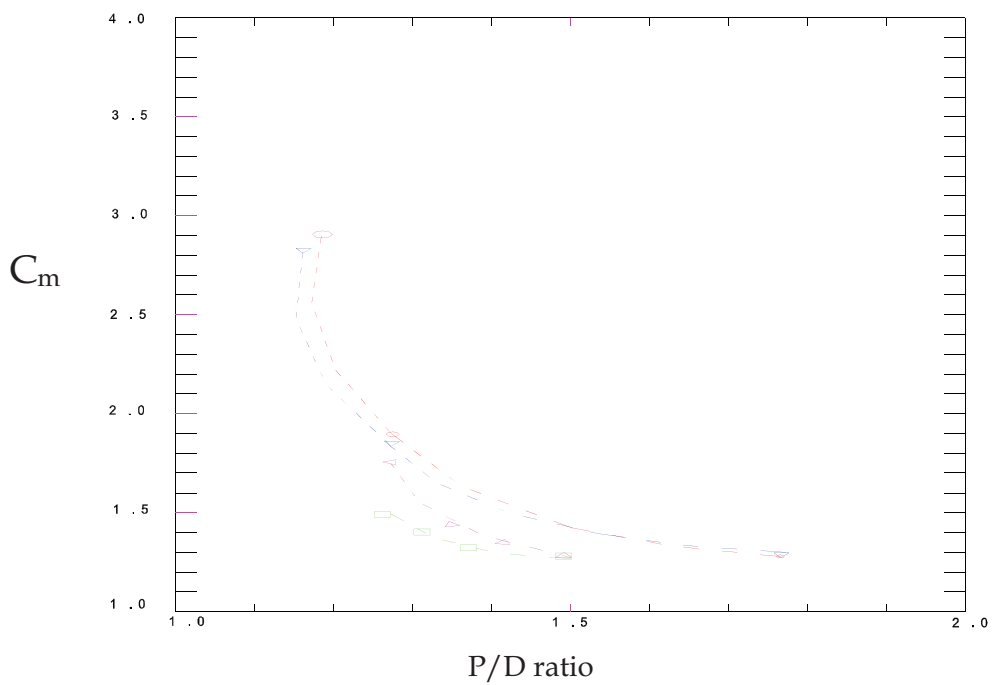

Fig. 13. Experimental $C_{m}$-values in tube bundles (Wambsganss et al., 1974, Moretti et al., 1976).

\subsection{Damping}

System damping has a strong influence on the amplitude of vibration. Damping depends upon the mechanical properties of the tube material, the geometry of intermediate supports and the physical properties of the shell-side fluid. Tight tube-to-baffle clearances and thick baffles increase damping, as does very viscous shell-side fluid (Chenoweth, 1993). (Coit et al., 1974) measured log decrements for copper-nickel finned tubes of 0.032 in still air. The range of most of the values probably lies between 0.01 and 0.17 for tubes in heat exchangers (Chenoweth, 1993). From (Wambsganss, et al., 1974), damping can be readily obtained from the transfer function or frequency response curve as 


$$
\zeta=\frac{1}{2 \sqrt{N^{2}-1}} \frac{\Delta f_{n}}{f_{n}}
$$

with $\Delta f_{n}=f_{N}^{(1)}-f_{N}^{(2)}$,

where $f_{n}$ is the resonant frequency and $f_{N}{ }^{(1)}$ and $f_{N}{ }^{(2)}$ are the frequencies at which the response is a factor $\frac{1}{N^{t h}}$ of resonant response.

(Lowery \& Moretti, 1975), have concluded that damping is almost entirely a function of the supports. More complex support conditions (non-ideal end supports or intermediate supports with a slight amount of clearance) lead to values around 0.04. From analytical point of view, (Jones, 1970) has remarked that in most cases, the addition of damping to the beam equation re-couples its modes. Only a beam, which has, as its damping function, a restricted class of functions can be uncoupled. (Chen et al., 1994) have found the fluid damping coefficients from measured motion-dependent fluid forces. (Pettigrew et al., 1986, 1991) outlines the energy dissipation mechanisms that contribute to tube damping as given in Table 6:

\begin{tabular}{|l|l|}
\hline \multicolumn{1}{|c|}{ Type of damping } & \multicolumn{1}{c|}{ Sources } \\
\hline Structural & Internal to tube material \\
\hline Viscous & Between fluid forces and forces transferred to fluid \\
\hline Flow-dependent & Varies with flow regime. \\
\hline Squeeze film & Between tube and fluid as tube approaches support \\
\hline Friction & Coulomb damping at support \\
\hline Tube support & Internal to support material \\
\hline Two-phase & Due to liquid gas mixture \\
\hline Thermal damping & Due to thermal load \\
\hline
\end{tabular}

Table 6. Energy dissipation mechanisms (Pettigrew et al., 1986, 1991)

\subsection{Parameters influencing damping}

(Pettigrew et al., 1986) further outlines the parameters that influence damping as given below:

The Type of tube motion. There are two principal types of tube motion at the supports, rocking motion and lateral motion. Damping due to rocking is likely to be less. Rocking motion is pre-dominant in lower modes. Dynamic interaction between tube and supports may be categorized in three main types, namely: sliding, impacting, and scuffing, which is impacting at an angle followed by sliding:

Effect of number of supports. The trend available in damping data referenced in (Pettigrew et al., 1986), when normalized give 


$$
\zeta_{n}=\zeta N /(N-1)
$$

where $\zeta_{n}$ is the normalized damping ratio, $N$ is the number of spans, and $\zeta$ is the damping ratio.

Effect of tube Frequency. Frequency does not appear to be significant parameter (Pettigrew et al., 1986).

Effect of vibration amplitude. There is no conclusive trend of damping as a function of amplitude. Very often, amplitude is not given is damping measurements (Pettigrew et al., 1986).

Effect of diameter or mass. Large and massive tubes should experience large friction forces and the energy dissipated should be large. However, the potential energy in the tube would also be proportionally large in more massive tubes. Thus, the damping ratio, which is related to the ratio of energy dissipated per cycle to the potential energy in the tube should be independent of tube size or mass (Pettigrew et al., 1986).

Effect of side loads. In real exchangers, side loads are possible due to misalignment of tubesupports or due to fluid drag forces. Side loads may increase or reduce damping. Small side loads may prevent impacting, and thus reduce damping, whereas large side loads may increase damping by increasing friction (Pettigrew et al., 1986).

Effect of higher modes. Damping appear to decrease with mode order, for mode order higher than the number of spans, since these higher modes involve relatively less interaction between tube and tube-support (Pettigrew et al., 1986).

Effect of tube support thickness. Referenced data in (Pettigrew et al., 1986) clearly indicates that support thickness is a dominant parameter. Damping is roughly proportional to support thickness. (Pettigrew et al., 1986) corrected the damping data line for support width less than $12.7 \mathrm{~mm}$ such that

$$
\zeta_{n c}=\zeta_{n}\left(\frac{12.7}{L}\right)
$$

where $L$ is support thickness in $\mathrm{mm}$ and $\zeta_{n c}$ is the corrected normalized damping ratio.

Effect of clearance. For the normal range of tube-to-support diametral clearances $(0.40 \mathrm{~mm}$ $0.80 \mathrm{~mm}$ ), there is no conclusive trend in the damping data reviewed (Pettigrew et al., 1986).

Design Recommendations (Pettigrew et al., 1986, 1991, Taylor et al., 1998)

Friction damping ratio in a multi-span tube (percentage)

$$
\begin{aligned}
& \text { (For liquid) } \zeta_{F}=0.5\left(\frac{N-1}{N}\right)\left(\frac{L}{l_{m}}\right)^{1 / 2} \\
& \text { (For gas) } \zeta_{F}=5.0\left(\frac{N-1}{N}\right)\left(\frac{L}{l_{m}}\right)^{1 / 2}
\end{aligned}
$$


where $N$ is the number of tube spans, $L$ is the support thickness, $l_{m}$ is the characteristic span length usually taken as average of three longest spans.

\section{Viscous damping ratio}

Rogers simplified version of Chens' cylinder viscous damping ratio (percentage) of a tube in liquid.

$$
\zeta_{F}=\frac{100 \pi}{\sqrt{8}}\left(\frac{\rho D^{2}}{m}\right)\left(\frac{2 v}{\pi f D^{2}}\right)^{1 / 2}\left[\frac{1+\left(D / D_{e}\right)^{3}}{\left(1-\left(D / D_{e}\right)^{2}\right)^{2}}\right]
$$

where $\rho$ is the fluid density, $m$ is the mass per unit length of tube (interior fluid and hydrodynamic mass), $D_{e}$ is the equivalent diameter to model confinement due to surrounding tubes, $D$ is the tube diameter, $f$ is the frequency of tube vibration and $v$ is the fluid kinematic viscosity. The term $S=\frac{\pi f D^{2}}{2 v}$ is the Stoke number.

\section{Squeeze film damping ratio}

$$
\text { (For multi-span tube) } \zeta=\left(\frac{N-1}{N}\right)\left(\frac{1460}{f}\right)\left(\frac{\rho D^{2}}{m}\right)\left(\frac{L}{l_{m}}\right)^{1 / 2}
$$

\section{Support damping}

(Pettigrew, et al., 1991) has developed a semi-empirical expression to formulate support damping, using Mulcahys' theory (Mulcahy, 1980).

$$
\zeta_{s}=\left(\frac{N-1}{N}\right)\left(\frac{2200}{f}\right)\left(\frac{\rho D^{2}}{m}\right)\left(\frac{L}{l_{m}}\right)^{0.6}
$$

(TEMA, 6th Edition, 1978, TEMA, 7th Edition, 1988)

According to TEMA standards, $\zeta$ is equal to greater of $\zeta_{1}$, and $\zeta_{2}$

(For shell-side liquids)

$$
\begin{gathered}
\zeta_{1}=\frac{3.41 d_{o}}{W_{o} f_{n}} \\
\zeta_{2}=\frac{0.012 d_{o}}{W_{o}}\left[\frac{\rho_{o} v}{f_{n}}\right]^{1 / 2}
\end{gathered}
$$

where $v$ is the shell fluid velocity, $d_{o}$ is the outside tube diameter, $\rho_{o}$ is the density of shellside fluid, $f_{n}$ is the fundamental frequency of tube span, and $W_{o}$ is the effective tube weight.

(For shell-side vapors) 


$$
\zeta=0.314 \frac{N-1}{N}\left(\frac{t_{b}}{l}\right)^{1 / 2}
$$

where $N$ is the number of spans, $t_{b}$ is the baffle or support plate thickness, and $l$ is the tube unsupported span. A review of two-phase flow damping is presented by (Khushnood et al., 2003).

\section{Damage numbers for collision and baffle damage (Chenoweth, 1976, Shin et al., 1975, Brothman et al., 1974)}

Two types of vibration damage are prevalent in cross-flow regions of steam generators (Shin \& Wambsganss, 1975).

- Tube-to-baffle impact.

- Tube-to-tube collision.

(Thorngren, 1970) deduced "damage numbers" for the two types of damage, based on the assumption that tube is supported by baffles and deflected by a uniformly distributed lift force. These damage numbers are given by following equations:

$$
\begin{gathered}
\text { (Baffle damage number) } N_{B D}=\frac{d \rho V^{2} l^{2}}{\beta_{1} S_{m} g_{c} A_{m} B_{t}} \\
\text { (Collision damage number) } N_{C D}=\frac{0.625 d \rho V^{2} l^{4}}{\beta_{1}^{4} g_{c} A_{m}\left(d^{2}+d_{i}^{2}\right) C_{T} E}
\end{gathered}
$$

where

$N_{B D}<1$ for safe design.

$N_{C D}<1$ for safe design.

$C_{T}=$ Maximum gap between tubes.

$d=$ Tube outer diameter.

$d_{i}=$ Tube inner diameter.

$\beta_{1}=$ Tube-to-baffle-hole clearance factor.

$E=$ Modulus of elasticity .

$g_{c}=$ Gravitational constant.

$B_{t}=$ Baffle thickness.

$\rho=$ Mass density of shell side fluid.

$l=$ Length of tube between supports.

$V=$ Free stream velocity.

$A_{m}=$ Tube cross-sectional area $\left[\frac{\pi}{4}\left(d^{2}-d_{i}^{2}\right)\right]$ and

$S_{m}=$ Maximum allowable fatigue stress [ASME Pressure Vessel code Sec. III].

Collision damage is usually predicted together with baffle damage, whereas the latter can be predicted without collision damage being indicated, i.e., baffle damage is important factor when appraising design (Erskine et al., 1973). (Burgreen et al., 1958) were the first to conduct an experiment to investigate vibration of tube for fluid flowing parallel to tube axis. (Quinn, 1962) and (Paidoussis, 1965) have developed analytical and empirical expressions respectively for peak amplitude. Paidoussis give the following expression: 


$$
\frac{\Delta}{d}=\alpha_{1}^{-4} \frac{U^{1.6} \varepsilon^{1.8} R_{e}^{0.25}}{I+U^{2}}\left(\frac{d_{h}}{d}\right)^{0.4} \frac{\beta^{2 / 3}\left(5 \times 10^{-4} \times K_{p}\right)}{I+4 \beta}
$$

where

$\begin{array}{lll}K_{p} & = & \text { Flow condition constant } \\ \Delta & = & \text { Maximum vibration amplitude at mid-span } \\ d & = & \text { Outer diameter of tube } \\ \alpha_{1} & = & \text { First mode beam eigen value of the tube } \\ U & = & \text { Dimensionless flow velocity } \\ \varepsilon=\frac{\ell}{d} & \\ \ell & = & \text { Tube length } \\ d_{h} & = & \text { Hydraulic diameter } \\ R_{e} & = & \text { Reynolds number } \\ I & = & \text { Moment of inertia and } \\ \beta & = & \text { Added mass fraction }\end{array}$

Later on a number of expressions for peak and RMS amplitudes have been developed (Shin et al., 1975, Blevins, 1977).

\section{Wear work-rates}

In fretting wear, work-rate is defined as the rate of energy dissipation when a tube is in contact with its support. Energy is being dissipated through friction as the tube moves around in contact with its supports. A force (the contact force between tube and support) multiplied by a displacement (as the tube slides) results in work or dissipated energy required to move the tube (Taylor et al., 1998, Au-Yang, 1998). Normal work-rate $W_{n}$ for different tube and tube support plate material combinations and different geometries (AuYang, 1998) is defined.

$$
W_{n}=\frac{1}{T} \int_{0}^{T}\left|F_{n}\right| d S
$$

where $T$ is the total time, $F_{n}$ is the normal contact force, and $S$ is the sliding distance.

(Au-Yang, 1998) has assessed the cumulative tube wall wear after 5, 10, and 15, effective full power years of operation of a typical commercial nuclear steam generator, using different wear models.

The EPRI data reproduced from (Hofmann \& Schettlet, 1989) in Figure 14 shows the wear volume against normal work-rate for the combination of Inconel 600 tube (discrepancy as plot shows J 600 whereas text indicates Inconel 600) and carbon tube support plate, a condition that applies to many commercial nuclear steam generators (Hofmann \& Schettlet, 1989). Figure 15 shows the tube wall thickness loss against volumetric wear for different support conditions (Hofmann \& Schettlet, 1989). 


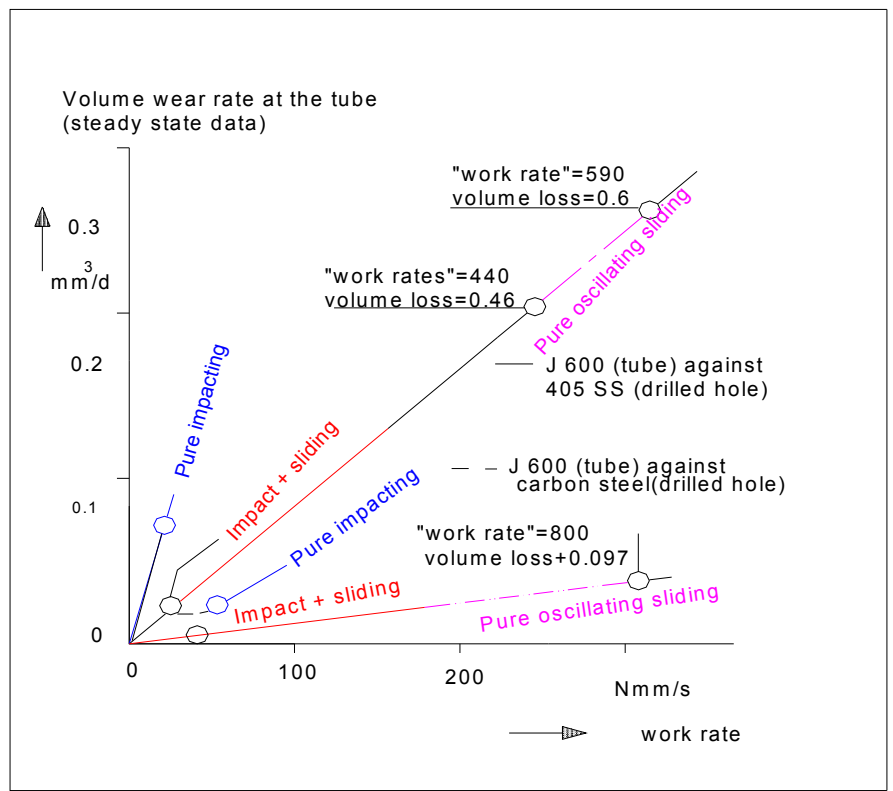

Fig. 14. Volumetric wear rate versus normal work-rate for different material combinations (Hofmann \& Schettlet, 1989).

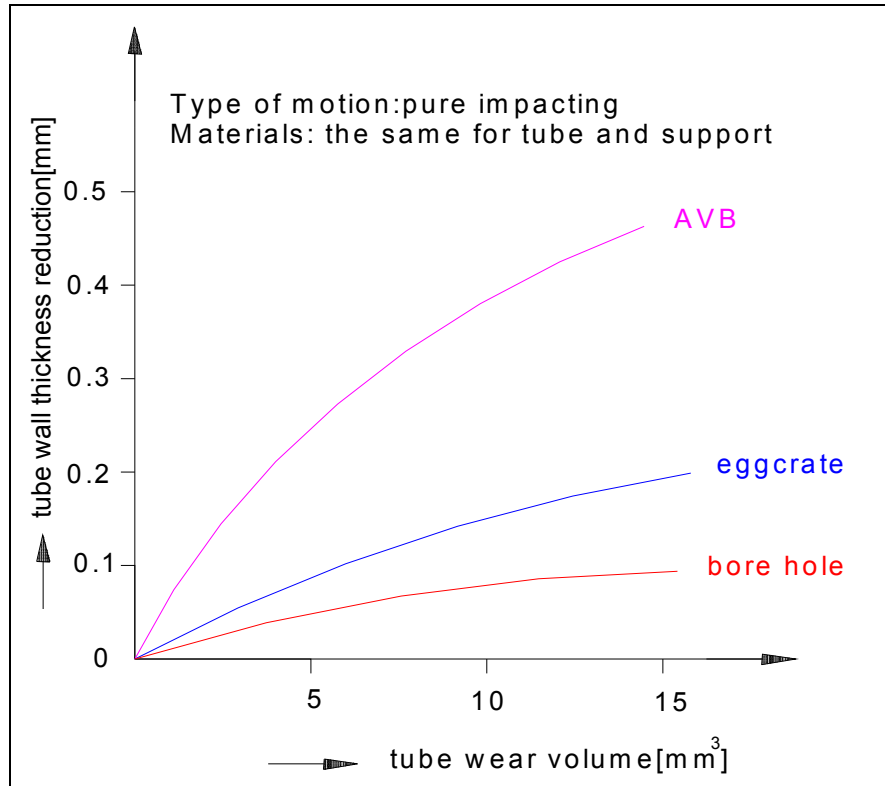

Fig. 15. Tube wall thickness loss versus volumetric wear for different support conditions, from Hofmann and Schettler (Hofmann \& Schettlet, 1989). 
(Payen et al., 1995) have carried predictive analysis of loosely supported tubes vibration induced by cross-flow turbulence for non-linear computations of tube dynamics. They have analyzed the gap effect and have concluded that wear work-rate decreases when the gap value increase at low velocities. (Peterka, 1995) has carried out numerical simulation of the tubes impact motion with generally assumed oblique impacts. (Charpentier and Payen, 2000) have carried out prediction of wear work-rate and thickness loss in tube bundles under cross-flow by a probabilistic approach. They have used Archard's Law and wear correlation depending on the contact geometry, and have concluded that most sensitive parameters that affect the wear work-rate are the coefficient of friction, the radial gap and the spectral level of turbulent forces.

(Paidoussis \& Li, 1992) and (Chen et al., 1995) have studied the chaotic dynamics of heat exchanger tubes impacting on the generally loose baffle plates, using an analytical model that involves delay differential equations. They have developed a Lyapunov exponent technique for delay differential equations and have shown that chaotic motions do occur. They have performed analysis by finding periodic solutions and determining their stability and bifurcations with the Poincare map technique. Hopf bifurcation is defined as the loss of stable equilibrium and onset of amplified oscillation (Paidoussis \& Li, 1992).

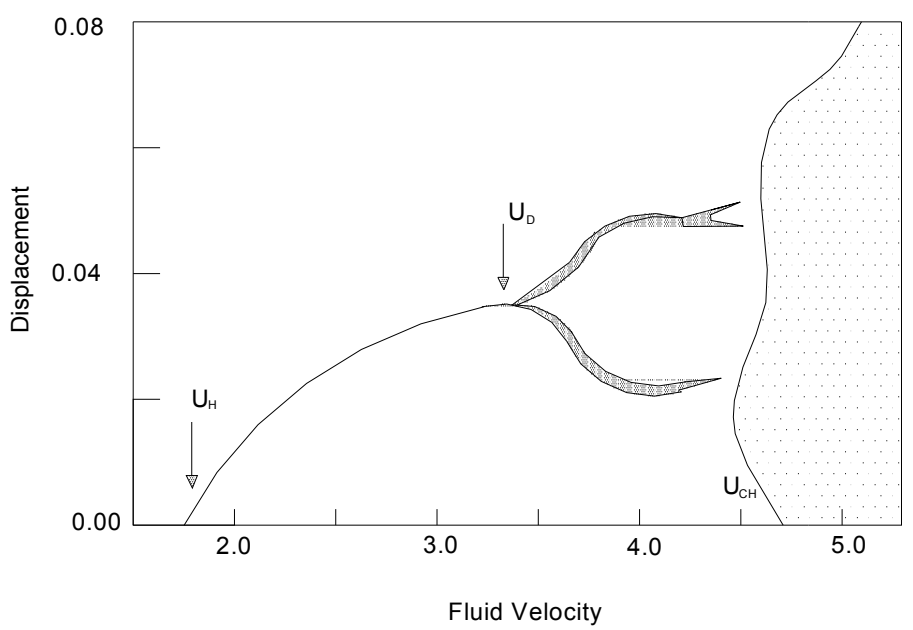

Fig. 16. The bifurcation diagram (Paidoussis \& Li, 1992, Chen et al., 1995)

A typical bifurcation diagram for the symmetric cubical model with $P / D=1.5$, is given in Figure 16 showing dimensionless mid-point displacement amplitude in terms of dimensionless fluid velocity. Where $U_{H}$ denotes critical $U$ for Hopf bifurcation, $U_{D}$, is the first post Hopf bifurcation, and $U_{C H}$ denotes the onset of chaos. Total wear work rates against pitch velocity and mass flux have been given by (Taylor et al., 1995) and (Khushnood et al., 2003). 


\begin{tabular}{|c|c|}
\hline Researchers & Salient fretting - wear features \\
\hline $\begin{array}{l}\text { (Rubiolo \& } \\
\text { Young, 2009) }\end{array}$ & $\begin{array}{l}\text { - } \quad \text { The evaluation of turbulence excitation is very challenging. } \\
\text { - } \quad \text { Identification of key wear factors that can be correlated to } \\
\text { assembly operating conditions. } \\
\text { - } \quad \text { Functional dependence of wear damage against identified factors. } \\
\text { - } \quad \text { Grid cell clearance size and turbulence forces as key risk factors for } \\
\text { - } \quad \text { Grid misalignment and cell tilts are less important. } \\
\text { - } \quad \text { Minimization of wear risk through modification in core loading. }\end{array}$ \\
\hline $\begin{array}{l}\text { (Jong \& Jung, } \\
\text { 2008) }\end{array}$ & $\begin{array}{l}\text { - } \quad \text { Fretting wear in helical coil tubes steam generator. } \\
\text { - } \quad \text { Thermal-Hydraulic prediction through FEM. } \\
\text { - } \quad \text { hemphasis on the effects of number of supports, coil diameter and } \\
\text { - } \quad \text { Design guidelines for designers and regulatory reviewers. }\end{array}$ \\
\hline (Attia, 2006a) & $\begin{array}{l}\text { Investigation of fretting wear of } \mathrm{Zr}-2.5 \% \mathrm{Nb} \text { alloy. } \\
\text { - } \quad \text { Experimental setup includes special design fretting wear } \\
\text { tribometers. } \\
\text { - } \begin{array}{l}\text { Fretting wear is initially dominated by adhesion and abrasion and } \\
\text { - } \quad \text { Volumetric wear loss decreased with number of cycles. }\end{array} \\
\end{array}$ \\
\hline (Attia, 2006b) & $\begin{array}{l}\text { - } \quad \text { Fitness for service and life management against fretting fatigue. } \\
\text { - } \quad \text { Examples of fretting problems encountered in nuclear power } \\
\text { - } \quad \text { Methodology to determine root cause. } \\
\text { - } \quad \text { Critical role of validation experimentally (long term) under } \\
\text { realistic conditions and to qualify in-situ measurements of fretting } \\
\text { damage non-destructive testing. }\end{array}$ \\
\hline (Rubiolo, 2006) & $\begin{array}{l}\text { - } \quad \text { Probabilistic method of fretting wears predictions in fuel rods. } \\
\text { - Non-linear vibration model VITRAN (Vibration Transient } \\
\text { Analysis). } \\
\text { - } \quad \text { Numerical calculations of grid work and wear rates. } \\
\text { - } \quad \text { variability of fuel assemble parameters). } \\
\text { Design preference of fuel rods. }\end{array}$ \\
\hline $\begin{array}{l}\text { (Kim et al., } \\
\text { 2006) }\end{array}$ & $\begin{array}{l}\text { - A way toward efficient of restraining wear. } \\
\text { - Increase in contact area through two different contours of spacer } \\
\text { grid spacing. } \\
\text { - Consideration of contact forces, slip displacement and wear scars } \\
\text { on rods to explore mechanical damage phenomenon. } \\
\text { It concludes that the contact shape affects the feature and behavior } \\
\text { of length, width and volumetric shape of wear. } \\
\text { A new parameter "equivalent depth" is introduced to represent } \\
\text { wear severity. }\end{array}$ \\
\hline
\end{tabular}

Table 7. Salient features of some recent researches on fretting wear Damage in Tube Bundles. 
A generalized procedure to analyze fretting - wear process and its self - induced changes in properties of the system and flow chart for fretting fatigue damage prediction with the aid of the principles of fracture mechanics is presented in figure $17 \& 18$ respectively.

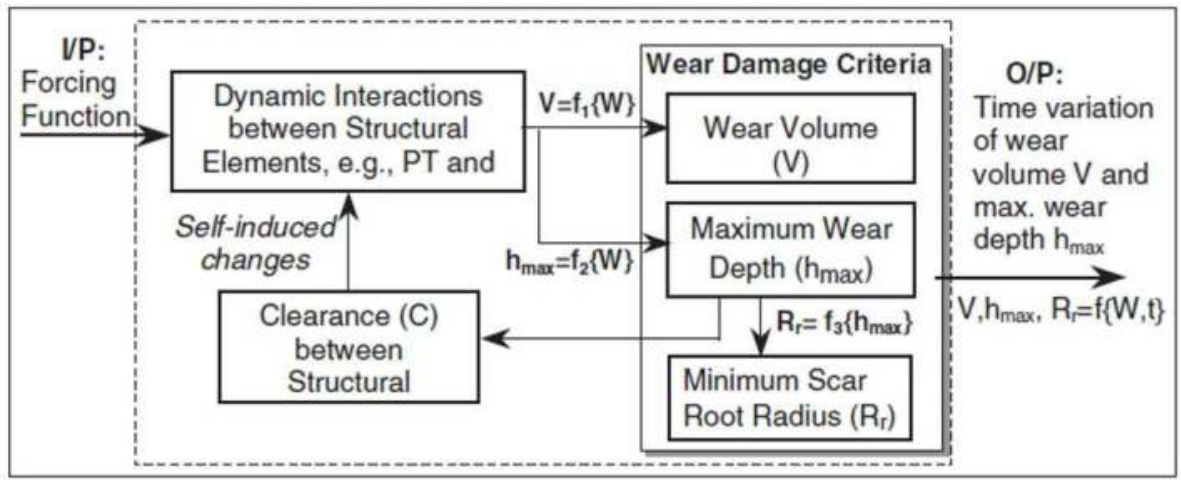

Fig. 17. System approach to the fretting wear process and its self-induced changes in the system properties (Attia, 2006a).

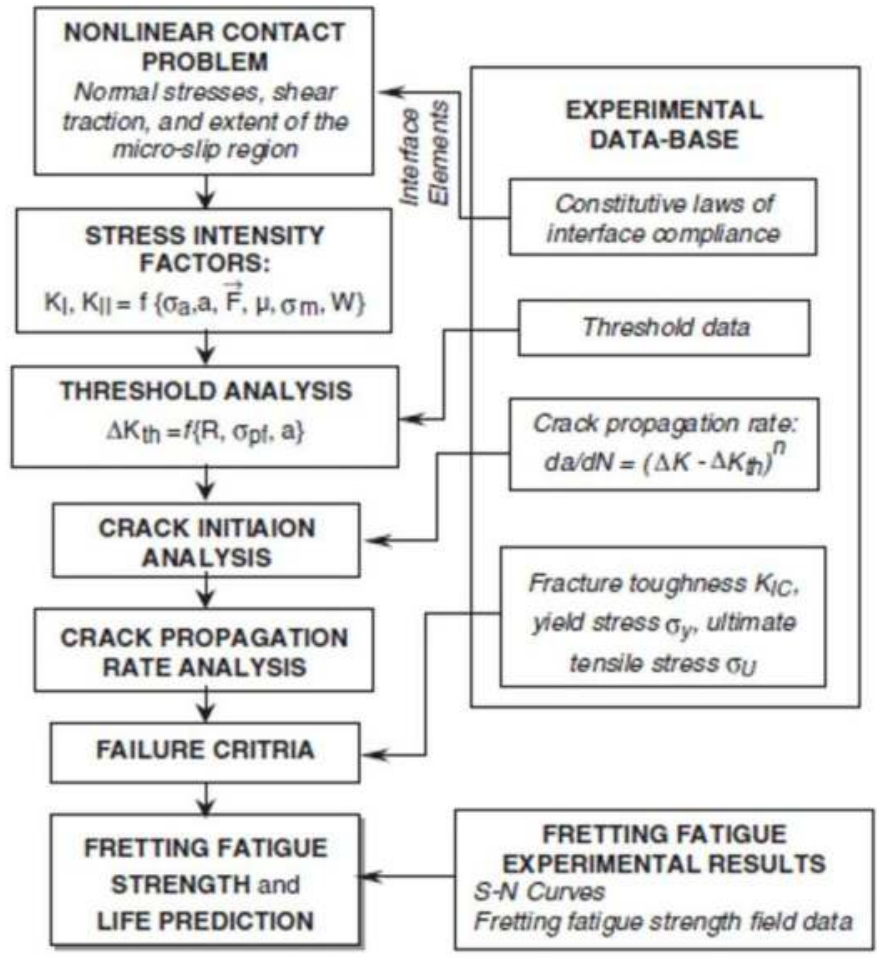

Fig. 18. Flow chart for the prediction of fretting fatigue damage, using fracture mechanics principles (Attia, 2006 ). 


\section{Tube bundle vibrations in two-phase cross-flow}

\subsection{Modeling two-phase flow}

Most of the early experimental research in this field relied on sectional models of tube arrays subjected to single-phase fluids such as air or water, using relatively inexpensive flow loops and wind tunnels. The cheapest and simplest approach to model two-phase flow is by mixing air and water at atmospheric pressure. However, air-water flows have a much different density ratio between phases than steam-water flow and this will affect the difference in the flow velocity between the phases. The liquid surface tension, which controls the bubble size, is also not accurately modeled in air-water mixtures. Table 8 gives the comparison of liquid and gas phase of refrigerants R-11, R-22 and air-water mixtures at representative laboratory conditions with actual steam-water mixture properties at typical power plant conditions (Feentra et al., 2000). This comparison reveals that the refrigerants approximate the liquid surface tension and liquid dynamic viscosity of steam-water mixtures more accurately than air-water mixtures.

\begin{tabular}{|l|c|c|c|c|}
\hline Property & R-11 & Air-water & R-22 & Steam-water \\
\hline Temperature $\left({ }^{0} \mathrm{C}\right)$ & 40 & 22 & 23.3 & 260 \\
\hline Pressure $(\mathrm{kPa})$ & 175 & 101 & 1000 & 4690 \\
\hline Liquid Density $\left(\mathrm{kg} / \mathrm{m}^{3}\right)$ & 1440 & 998 & 1197 & 784 \\
\hline Gas Density $\left(\mathrm{kg} / \mathrm{m}^{3}\right)$ & 9.7 & 1.18 & 42.3 & 23.7 \\
\hline Liquid kinematic viscosity $\left(\mu \mathrm{m}^{2} / \mathrm{sec}\right)$ & 0.25 & 1.0 & 0.14 & 0.13 \\
\hline Gas kinematic Viscosity $\left(\mu \mathrm{m}^{2} / \mathrm{sec}\right)$ & 1.2 & 1.47 & 0.30 & 0.75 \\
\hline Liquid Surface Tension $(\mathrm{N} / \mathrm{m})$ & 0.016 & 0.073 & 0.0074 & 0.0238 \\
\hline Density Ratio & 148 & 845 & 28.3 & 33 \\
\hline Viscosity Ratio & 0.20 & 0.70 & 0.47 & 0.17 \\
\hline
\end{tabular}

Table 8. Comparison of properties of air-water, R-22, and R-11 with steam-water at plant conditions (Feentra et al., 2000)

Typical nuclear steam generators such as those used in the CANDU design utilize more than 3000 tubes, $13 \mathrm{~mm}$ in diameter, formed into an inverted U-shape. In the outer U-bend region, these tubes are subject to two-phase cross-flow of steam-water which is estimated to be of $20 \%$ quality. It is highly impractical and costly to perform flow- induced vibration experiments on a full-scale prototype of such a device so that small-scale sectional modeling is most often adopted. R-11 simulates the density ratio, viscosity ratio and surface tension of actual steamwater mixtures better than air-water mixtures and it also allows for localized phase change which air-water mixture does not permit. While more costly and difficult to use than air-water mixture, R-11 is a much cheaper fluid to model than steam-water because it requires $8 \%$ of the energy compared with water to evaporate the liquid and operating pressure is much lower, thereby reducing the size and cost of the flow loop (Feentra et al., 2000).

\subsection{Representative published tests on two-phase flow across tube arrays}

Table 6, an extension of period beyond 1993 (Pettigrew et al., 1973) presents a summary of salient features of the experimental tests performed on the three possible tube arrangements (triangular, normal square, and rotated square). 


\begin{tabular}{|c|c|c|c|c|}
\hline Researchers & Fluid & Tube Array & Void Fraction & \\
\hline (Pettigrew et al., 1973) & Air-Water & $\begin{array}{l}\text { Triangular/ Parallel. } \\
\text { Square/Rotated Square }\end{array}$ & $\begin{array}{l}10-20 \% \\
\text { (quality) }\end{array}$ & \\
\hline (Heilker \& Vincent, 1981) & Air-Water & Triangular/ Rotated Square & $0.5-0.87$ & \\
\hline (Hara et al., 1981) & Air-Water & Single Tube & $0.02-0.61$ & \\
\hline (Remy, 1982) & Air-Water & Square & $0.65-0.85$ & 1 \\
\hline (Nakamura et al., 1982) & Air-Water & Square/ Rotated Square & $0.2-0.94$ & \\
\hline (Pettigrew et al., 1985) & Air-Water & Triangular/ Square & $0.05-0.98$ & \\
\hline (Axisa et al., 1984) & Steam-Water & Square & $0.52-0.98$ & 1 \\
\hline (Nakamura et al., 1986) & Steam-Water & Square & $0.75-0.95$ & \\
\hline (Hara, 1987) & Air-Water & Single/Row & $0.01-0.5$ & \\
\hline (Goyder, 1988) & Air-Water & Triangular & $0.5-0.8$ & \\
\hline (Gay et al., 1988) & Freon & Triangular & $0.58-0.84$ & \\
\hline (Nakamura \& Fujita, 1988) & Air-Water & Square & $0.02-0.95$ & \\
\hline (Funakawa et al., 1989) & Air-Water & Square/ Triangular & $0.0-0.6$ & 10 \\
\hline (Nakamura et al., 1990) & Steam-water & Square & $0.33-0.91$ & \\
\hline (Axisa et al., 1990) & Steam-water & $\begin{array}{l}\text { Square/ Triangular Parallel/ } \\
\text { Triangular }\end{array}$ & $0.52-0.99$ & \\
\hline (Papp \& Chen, 1994) & -- & $\begin{array}{l}\text { Normal triangular / Normal } \\
\text { Square/ Parallel Triangular }\end{array}$ & $25-98 \%$ & \\
\hline $\begin{array}{l}\text { (Pettigrew, Taylor, Jong \& } \\
\text { Currie, 1995) }\end{array}$ & Freon & Rotated triangular & $40-90 \% 10-90 \%$ & \\
\hline (Noghrehkar et al., 1995) & Air-Water & Square fifth \& sixth row & $0-90 \%$ & \\
\hline (Taylor et al., 1995) & Air-Water & $\begin{array}{l}\text { U-bend tube bundle with } 180^{0} \mathrm{U} \text { - } \\
\text { tubes parallel triangular } \\
\text { configuration }\end{array}$ & $0-90 \%$ & \\
\hline $\begin{array}{l}\text { Marn \& Catton (Marn \& } \\
\text { Catton, 1996) }\end{array}$ & Air-Water & $\begin{array}{l}\text { Normal triangular, Parallel } \\
\text { triangular, \& rotated square }\end{array}$ & $5-99 \%$ & \\
\hline (Taylor \& Pettigrew, 2000) & Freon & Rotated triangular \& Rotated Square & $50-98 \%$ & \\
\hline (Pettigrew et al., 2000) & Air-Water & $\begin{array}{l}\text { Normal } 30^{\circ} \& \text { rotated } 60^{\circ} \text { triangular, } \\
\text { Normal } 90^{\circ} \& \text { rotated } 45^{\circ} \text { square }\end{array}$ & $0-100 \%$ & \\
\hline
\end{tabular}




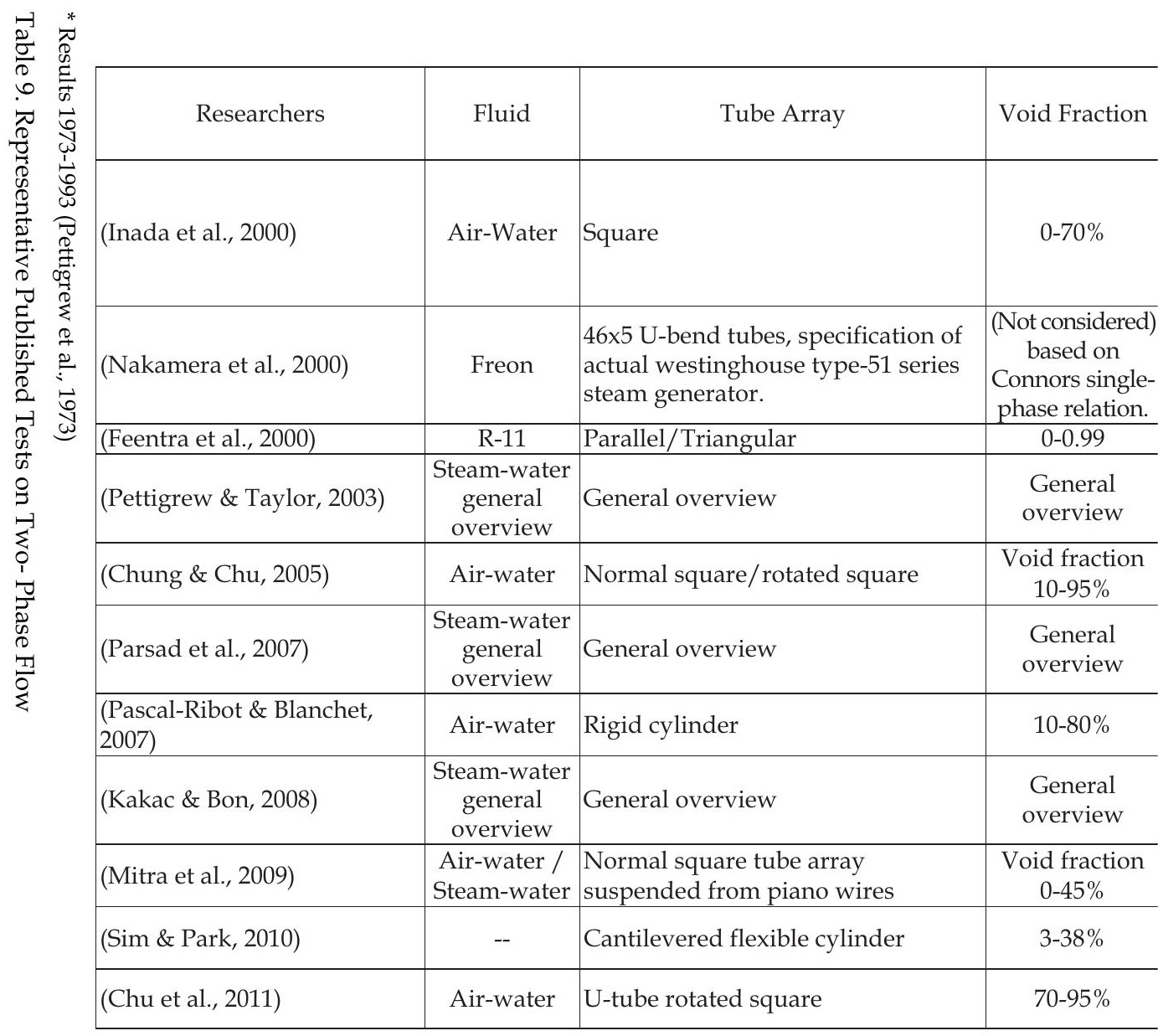




\subsection{Thermal hydraulic models}

Considering two-phase flow, homogenous flow assumes that the gas and liquid phases are flowing at the same velocity, while other models for two-phase flow, such as drift-flux assume a separated flow model with the phases allowed to flow at different velocities. Generally the vapor flow is faster in upward flow because of the density difference.

\subsubsection{The homogenous equilibrium model}

Homogenous Equilibrium Model (HEM) treats the two-phase flow as finely mixed and homogeneous in density and temperature with no difference in velocity between the gas and liquid phases.

A general expression for void fraction $\alpha$, is given in (Feentra et al., 2000).

$$
\alpha=\left[1+S \frac{\rho_{G}}{\rho_{L}}\left(\frac{1}{x}-1\right)\right]^{-1}
$$

where $\rho_{G}$ and $\rho_{L}$ are the gas and liquid densities respectively and $S$ is the velocity ratio of the gas and liquid phase (i.e. $S=U_{G} / U_{L}$ ). The quality of the flow $x$ is calculated from energy balance, which requires measurement of the mass flow rate, the temperature of the liquid entering the heater, the heater power, and the fluid temperature in the test section. The HEM void fraction $\alpha_{H}$ is the simplest of the two-phase fluid modeling, whereby the gas and liquid phases are assumed to be well mixed and velocity ratio $S$ in Equation 36 is assumed to be unity. The average two-phase fluid density $\rho$ is determined by Equation 37 .

$$
\rho=\alpha \rho_{G}+(1-\alpha) \rho_{L}
$$

The HEM fluid density $\rho_{H}$ is determined using Equation 32 by substituting $\alpha_{H}$ in place of $\alpha$. The HEM pitch flow velocity $V_{P}$ is determined by

$$
V_{P}=G_{P} / \rho_{H}
$$

Where $G_{p}=$ Pitch mass flux

\subsubsection{Homogenous flow (Taylor \& Pettigrew, 2000)}

This model assumes no relative velocity between the liquid velocity $U_{1}$ and the gas velocity $U_{g}$. Slip $S$ between the two-phases is:

$$
\begin{gathered}
S=1: U_{h}=U_{g}=U_{1} ; \\
\varepsilon_{g}=\frac{j_{g}}{j_{g}+j_{l}}
\end{gathered}
$$

where $U_{h}$ is the homogeneous velocity, $U_{g}$ is the gas phase velocity, $U_{l}$ is the liquid phase velocity, $\varepsilon_{g}$ is the homogenous void fraction, $j_{g}$ is superficial gas velocity and $j_{l}$ is the superficial liquid velocity. 


\subsubsection{Smith correlation}

(Smith, 1968) assumes that kinetic energy of the liquid is equivalent to that of the two-phase mixture and a constant fraction $k$ of liquid phase is entrained with the gas phase. The value $k=0.4$ was chosen to correspond with the best agreement to experimental data for flow in a vertical tube. Using the Smith correlation, the slip is defined as follows.

$$
S=k+(1-k)\left[\frac{x \rho_{l} / \rho_{g}+k(1-x)}{x+k(1-x)}\right]^{1 / 2}
$$

where $x$ is the mass quality, $\rho_{g}$ is the density of the gas phase and $\rho_{1}$ is the density of the liquid phase.

\subsubsection{Drift-flux model}

The main formulation of drift-flux model was developed by (Zuber and Findlay, 1965). This model takes into account both the two-phase flow non-uniformity and local differences of velocity between the two phases. The slip is defined as follows.

$$
S=\frac{\left(1-\varepsilon_{g}\right)}{\frac{1}{C_{0}+\frac{\overline{U_{g j}}}{j}}-\varepsilon_{g}}=\frac{C_{0}+\frac{\overline{U_{g j}}}{j}-\frac{x}{x\left(1-\frac{\rho_{g}}{\rho_{l}}\right)+\frac{\rho_{g}}{\rho_{l}}}}{1-\frac{x}{x\left(1-\frac{\rho_{g}}{\rho_{l}}\right)+\frac{\rho_{g}}{\rho_{l}}}}
$$

where $\overline{U_{g j}}$ is averaged gas phase drift velocity.

$$
j=j_{g}+j_{l}=\dot{m}\left(\frac{x}{\rho_{g}}+\frac{(1-x)}{\rho_{l}}\right)
$$

Where $\dot{m}$ is the mass flux

The remaining two unknowns are empirical and (Lellouche et al., 1982) is used to estimate these.

$$
C_{0}=\frac{L}{K_{1}+\left(1-K_{1}\right) \varepsilon_{g}^{r}}
$$

\subsubsection{Schrage correlation}

The correlation by (Schrage, 1988) is based on empirical data from an experimental test section, which measures void fraction directly. This test section has two valves capable of isolating a part of the flow almost instantaneously.

The correlation is based on physical considerations and assumes two different hypotheses: 
The Schrage correlation is as follows:

$$
\varepsilon_{g} / \varepsilon_{g h}=1+0.123 \mathrm{Fr}^{-0.191} \ln \mathrm{x}
$$

with

$$
\mathrm{F}_{\mathrm{r}}=\dot{m} / \rho_{l} \sqrt{g D}
$$

This correlation was established with an air-water mixture, but it remains valid for any other phase flow.

\subsubsection{Feenstra model}

In this model (Feentra et al., 2000), predicted velocity ratio of the phases is given by

$$
\mathrm{S}=1+25.7\left(\mathrm{R}_{\mathrm{i}} \times \mathrm{Cap}\right)^{0.5}(\mathrm{P} / \mathrm{D})^{-1}
$$

Where Cap is the capillary number and $\mathrm{R}_{\mathrm{i}}$ is the Richardson number

\subsubsection{Comparison of void fraction models}

The HEM greatly over-predicts the actual gamma densitometer void fraction measurement and the prediction of void fraction model by Feenstra et al., is superior to that of other models. It also agrees with data in literature for air-water over a wide range of mass flux and array geometry (Feentra et al., 2000). The main problem with using the HEM is that it assumes zero velocity ratios between the gas and liquid phases. This assumption is not valid in the case of vertical upward flow, because of significant buoyancy effects.

\subsection{Dynamic parameters}

\subsubsection{Hydrodynamic mass}

Hydrodynamic mass $m_{h}$ is defined as the equivalent external mass of fluid vibrating with the tube. It is related to the tube natural frequency $f$ in two-phase mixture as discussed in (Carlucci \& Brown, 1997) and is given below:

$$
m_{h}=m_{t}\left[\left(f_{g} / f\right)^{2}-1\right]
$$

where $m_{t}$ is the mass of tube alone and $f_{g}$ is the natural frequency in air.

Hydrodynamic mass depends on the pitch-to-diameter ratio of the tube, and is given by (Pettigrew et al., 1989)

$$
m_{h}=\left(\frac{\rho \pi d^{2}}{4}\right)\left[\frac{\left(D_{e} / d\right)^{2}+1}{\left(D_{e} / d\right)^{2}-1}\right]
$$

where $\rho$ is the two-phase mixture density. 


$$
\begin{gathered}
D_{e} / d=(0.96+0.5 P / d) P / d, \text { for a triangular bundle. } \\
D_{e} / d=(1.07+0.56 P / d) P / d, \text { for a square bundle. }
\end{gathered}
$$

where $D_{e}$ is equivalent diameter to model confinement due to the surrounding tubes as given by (Rogers et al., 1984).

Early air-water studies (Carlucci, 1980) showed that added mass decreases with the void fraction as shown in Figure 19. It is also less than $(1-\alpha)$, where $\alpha$ is the void fraction. This deviation from expected $(1-\alpha)$ line is caused by the air bubble concentrate at the flow passage center. Surprisingly added mass has attracted very little attention of researchers which is a potential avenue for future researches.

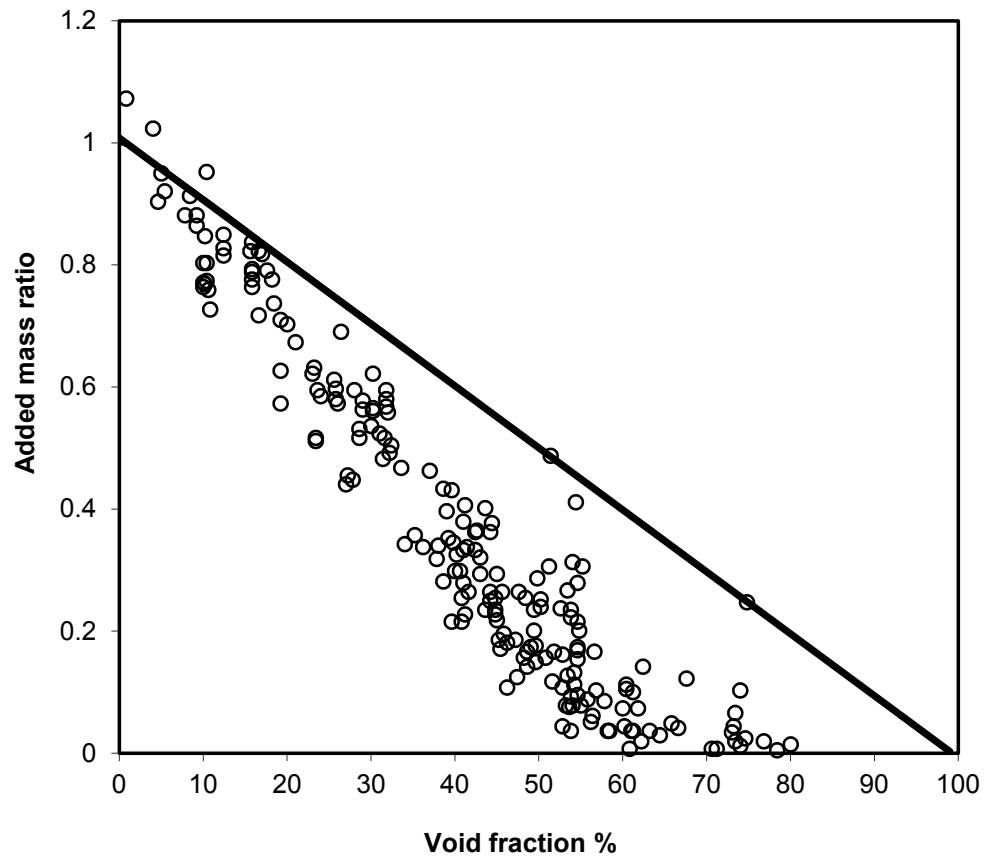

Fig. 19. Added mass as a function of void fraction (Carlucci, 1980).

\subsubsection{Damping in two-phase}

Subtracting the structural damping ratio from the total yields the two-phase fluid-damping ratio (Noghrehkar et al., 1995). Total damping includes structural damping, viscous damping and a two-phase component of damping as explained by (Pettigrew et al. 1994). The damping ratio increases as the void fraction increases and peaks at $60 \%$ (Carlucci, 1983), then the ratio decrease with $\alpha$ (Figure 20). Damping also decreases as the vibration frequency increases (Pettigrew et al., 1985). 


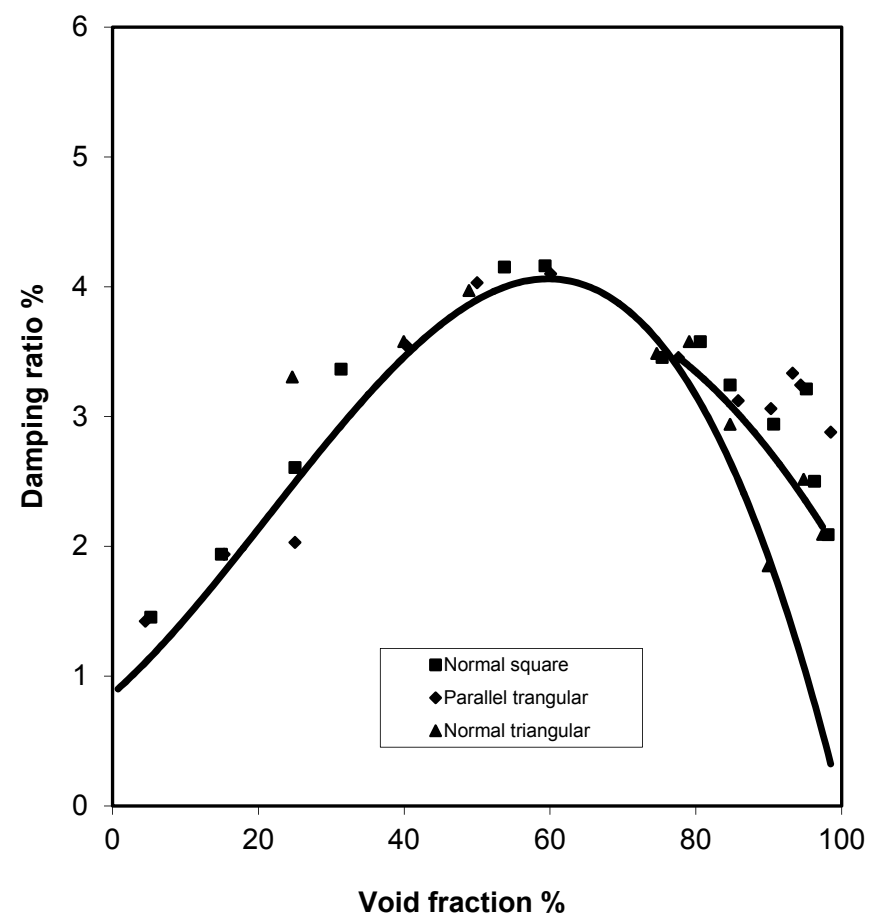

Fig. 20. Damping ratio as a function of void fraction (Carlucci, 1983).

Damping in two-phase is very complicated. It is highly dependent upon void fraction and flow regime. The results for the two-phase component of damping can be normalized to take into account the effect of confinement due to surrounding tubes by using the confinement factor $C$ (Pettigrew et al., 2000). This factor is a reasonable formulation of the confinement due to $P / D$. As expected, greater confinement due to smaller $P / D$ increase damping. The confinement factor is given by equation below:

$$
C=\frac{\left[1+\left(D / D_{e}\right)^{3}\right]}{\left[1-\left(D / D_{e}\right)^{2}\right]^{2}}
$$

\subsection{Flow regimes}

Many researchers have attempted the prediction of flow regimes in two-phase vertical flow. As yet, a much smaller group has examined flow regimes in cross-flow over tube bundles. Some of the first experiments were carried out by I.D.R. Grant (Collier, 1979) as it was the only available map at the time. Early studies in two-phase cross-flow used the Grant map to assist in identifying tube bundle flow regimes (Pettigrew et al., 1989) and (Taylor et al., 1989). More recently, Ulbrich \& Mewes [180] performed a comprehensive analysis of available flow regime data resulting in a flow regime boundaries that cover a much larger 
range of flow rates. They found that their new transition lines had an $86 \%$ agreement with available data. Their flow map is shown in Figure 21 by (Feenstra et al., 1990) with the flow regime boundary transitions in solid lines and the flow regimes identified with upper-case text. The dotted lines outline a previous flow regime map based on Freon-11 flow in a vertical tube from (Taitel et al., 1980).

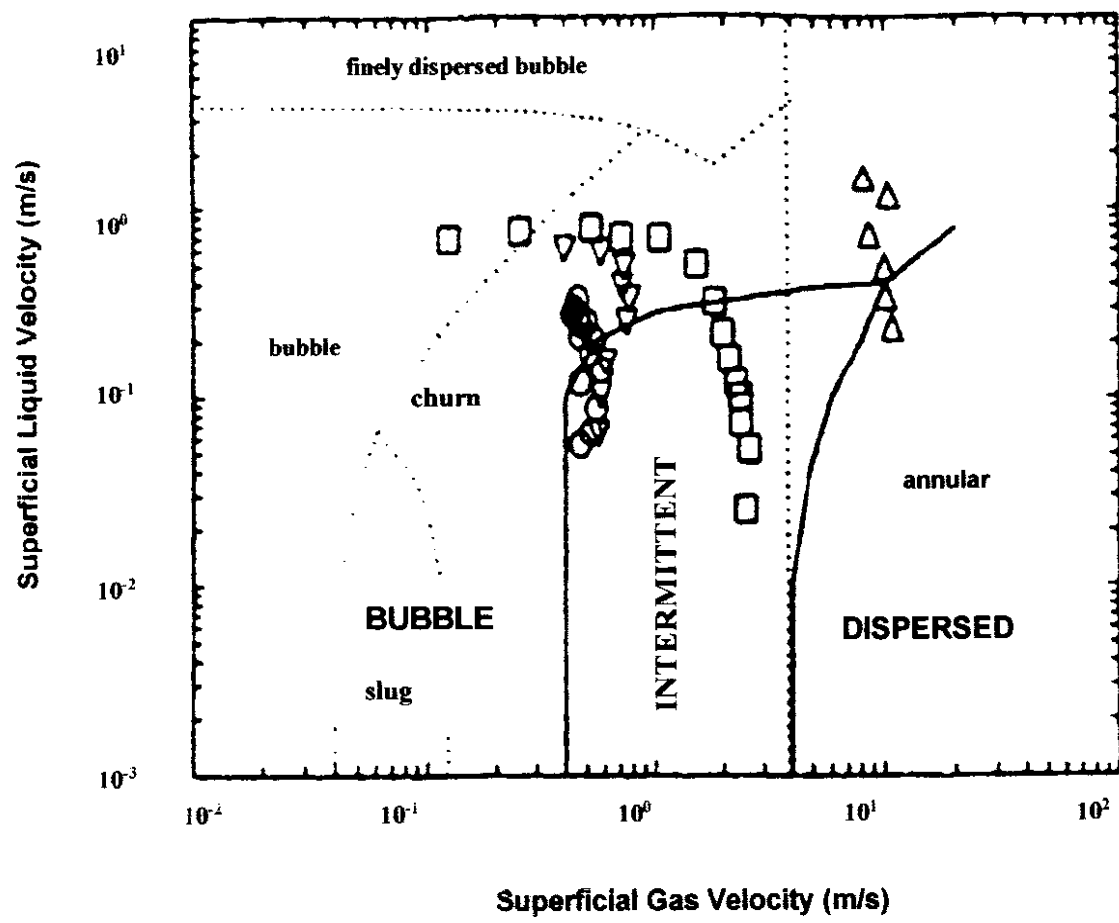

Fig. 21. Flow regime map for vertically upward two-phase flow: From (Feenstra et al., 1986, Taitel et al., 1980). $\square$ (Pettigrew et al., 1989), $\Delta$ (Axisa, 1985), $\nabla$ (Pettigrew et al., 1995), O (Feenstra et al., 1995).

Almost every study of flow regimes in tube bundles has concluded that three distinct flow regimes exist. In fact, several studies have shown that these regimes can easily be identified by measuring the probability density function (PDF) of the gas component of the flow (Ulbrich \& Mewes, 1997), (Noghrehkar et al., 1995) and (Lian et al., 1997).

\subsection{Tube to restraint interaction (wear work-rate)}

Significant tube-to-restraint interaction can lead to fretting wear. Large amplitude out-ofplane motion will result in large impact forces and in-plane motion will contribute to rubbing action. Impact force and tube-to-restraint relative motion can be combined to determine work-rate. Work-rate is calculated using the magnitude of the impact force and the effective sliding distance during line contact between the tube and restraint (Chen et al., 1995). The work-rate is given below in Equations 54 and 55. 


$$
\begin{gathered}
W=\frac{1}{T_{s}} \int_{i=0}^{n} F_{i} d S_{i} \\
W=\frac{1}{T_{s}} \sum_{i=0}^{n} F_{i} \Delta S_{i}=\frac{1}{T_{s}} \sum_{i=0}^{n} \frac{F_{i}+F_{i+1}}{2} \Delta S_{i}
\end{gathered}
$$

where $F_{i}$ is the instantaneous normal force, $\Delta S_{i}$ is the sliding distance during line contact and $n$ is the number of points discretized over the sample duration $T_{s}$. As the work-rate increases, the effective wear rate increases and the operational life of the U-bend tube decreases. Implementation of the technology is described in detail by (Fisher et al., 1991). Measured values of wear work-rate for pitch velocity and mass flux (Chen et al., 1995) are presented in Figures 22a and 22b respectively. The effect of fluid-elastic forces is very evident in the measured work-rates.

It is interesting to note that at higher pitch velocities and/or mass fluxes, the wear work-rate does not increase. Further study is required to understand why the flow-rates do not affect the work-rates. This may be related to the fact that at high void fractions and high flow rates the random excitation forces are constant with increasing flow rate (Taylor, 1992).

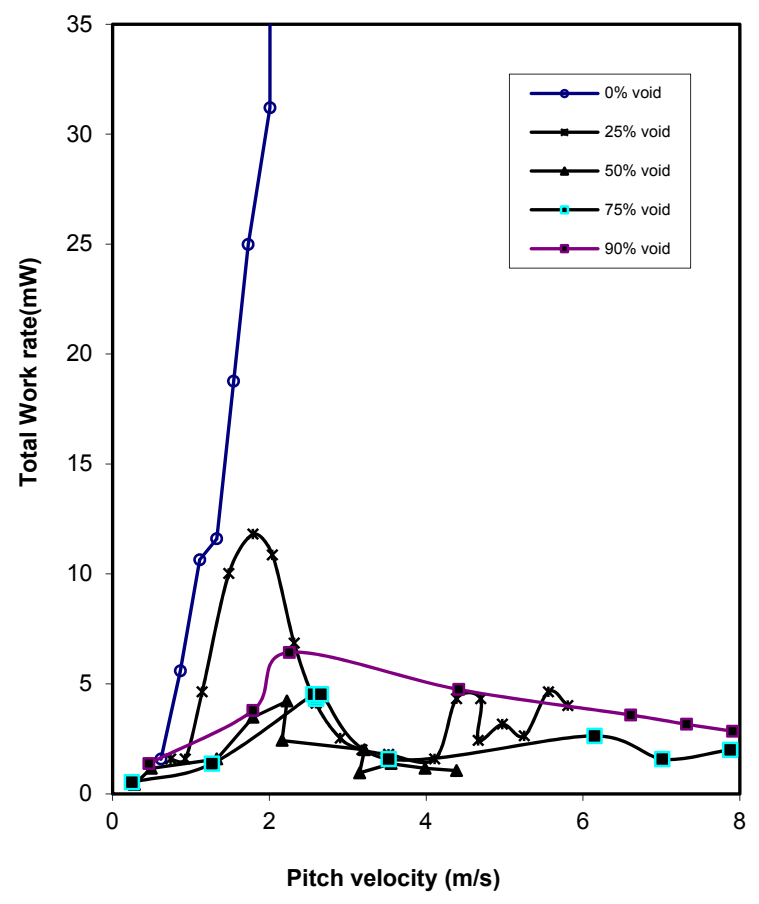

Fig. 22(a). Measured work-rate versus pitch velocity (Chen et al., 1995) 


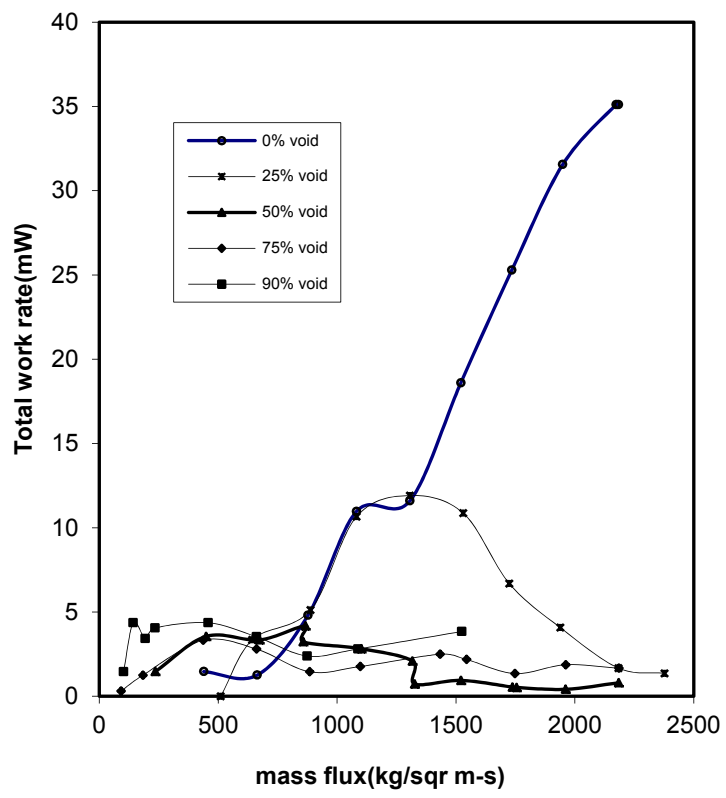

Fig. 22(b). Measured work-rate versus mass flux (Chen et al., 1995).

\subsection{Measurement of void fraction}

In general, the surveyed research indicates two types of void fraction measurements (Feentra et al., 2000). The HEM void fraction and RAD void fraction. HEM refers to Homogeneous Equilibrium Model and RAD refers to Radiation Attenuation Method. The determination of fluid parameters (fluid density and flow velocity) are quite different when these two methods are used (Feentra et al., 2000). In RAD method (Feenstra et al., 2000, Wright \& Bannister, 1970) gamma flux from radiation source which penetrates the test section will be attenuated by different amounts depending upon the average density of the two-phase flow. Void fraction $\alpha$ can be determined by interpolating the average density of the fluid between the benchmark measurements for one hundred percent liquid and gas according to the following equation.

$$
\alpha=\ln \left(N / N_{L}\right) / \ln \left(N_{G} / N_{L}\right)
$$

where $N$ represents the gamma counts obtained during an experimental trial, $N_{L}$ and $N_{G}$ are the reference counts obtained prior to the experiment for $100 \%$ liquid and $100 \%$ gas respectively. Gas phase velocity, $U_{G}$, and liquid phase velocity $U_{L}$ can be calculated by Equations below:

$$
U_{G}=\frac{x G_{P}}{\alpha \rho_{G}}
$$




$$
U_{L}=\frac{(1-x) G_{P}}{(1-\alpha) \rho_{L}}
$$

where $G_{p}$ is the pitch mass flux.

A logical measure of an equivalent two-phase velocity, $V_{e q}$ is determined from averaging the dynamic head of the gas and liquid phases as given by equation below:

$$
V_{e q}=\sqrt{\left[\alpha \rho_{G} U_{G}^{2}+(1-\alpha) \rho_{L} U_{L}^{2}\right] / \rho}
$$

\section{Conclusions}

Loss of Millions of Dollars through Cross-Flow-Induced-Vibrations related problems in steam generators and heat exchangers excitations has been a cause of major concern in process, power generation and nuclear industries. Flow-Induced Vibration pose a potential problem to designers, process engineers and plant operating and maintenance personnel. Such vibrations lead to motion of tubes in loose supports of baffles of tube bundles, resulting in mechanical damage, fretting wear, leaking and fatigue etc. Heat exchanger tubes are the most flexible components of the assembly. The risk of radiation exposure is always present in case of leakage in steam generator of PWR plants due to vibration related tube failures.

A number of design consideration have been reviewed in this chapter in order to achieve design improvements to support large scale heat exchangers with increased shell-side crossflow-velocities. The prime consideration is the natural frequency of tubes in a bundle against cross-flow-induced-vibrations. Various analytical, experimental and computational techniques for straight \& curved tubes have been discussed with reference to single and multiple spans and varying end and intermediate support conditions. Earlier, FlowInduced-Vibration analysis was based upon the concept of two types of damage numbers (Collision damage and baffle damage). Discussion on these damage numbers and on the parameters that influence damping has been included.

Next consideration is the generally accepted following four tube bundle vibration excitation mechanisms (various models have been discussed \& reviewed) including steady, unsteady, analytical, FEM based, CFD based, experimental, empirical correlation based, large eddy

\begin{tabular}{|c|c|c|}
\hline Turbulent Buffeting & - & $\begin{array}{l}\text { It can not be avoided in Heat Exchangers and } \\
\text { is caused due to turbulence. }\end{array}$ \\
\hline Vorticity Excitation & - & Vortex shedding or periodic wake Shedding \\
\hline Fluid-Elastic Instability & - & $\begin{array}{l}\text { Self excited vibration resulting from } \\
\text { interaction of tube motion and flow is the most } \\
\text { dangerous excitation mechanism. }\end{array}$ \\
\hline Acoustic Resonance & - & $\begin{array}{l}\text { Caused by some flow excitation having } \\
\text { frequency which coincides with natural } \\
\text { frequency. }\end{array}$ \\
\hline
\end{tabular}
simulation (LES) based, linear and non-linear etc. 
Dynamic parameters like added mass and damping which are function of geometry, density of fluid and tube size have been targeted by a number of researches in single-phase and two-phase flow. These researches have identified seven separate sources of damping which have been highlighted.

Tube wear due to non-linear tube-to-tube support plate interactions caused by gap clearances between interacting components resulting in thickness loss and normal wear work-rates have been reviewed. Chaotic dynamics of tubes impacting generally on loose baffle plates with consideration of stability and bifurcation have been discussed.

Two-phase Cross-Flow-Induced-Vibrations in tube bundles of process heat exchanger and U-bend region of Nuclear Steam generators can cause serious tube factures by fatigue and fretting wear. Solution to such problems require understanding of vibration excitation and damping mechanism in two-phase flow. This further requires consideration of different flow regimes which characterize two-phase flow. The discussion includes the most important parameter which is void fraction, various thermal-hydraulic models, dynamic parameters, wear work-rates, void fraction measurement and application of TEMA/ASME and other codes have been reviewed. In conclusion the objective of this chapter is to suggest improvements in the design guidelines from the available researches to use the related equipment at optimal performance level.

\section{Acknowledgements}

We are deeply indebted to University of Engineering \& Technology, Taxila - Pakistan, PASTIC, Islamabad - Pakistan and College of EME NUST, Rawalpindi - Pakistan for providing financial, administrative and technical support. We sincerely appreciate the support provided by Mr. Zahid Iqbal, Mr. Riffat Iqbal and Mr. Muhammad Shafique in finalizing the manuscript.

\section{References}

Antunes, J., Villard, B., Axisa, F., 1985," Cross-flow induced vibration of U-bend tubes of a steam-generator ", Proceedings of SMiRT, F-16/9, pp. 229-239.

Archer, R. R., 1960, "Small vibrations of thin incomplete circular rings", International Journal of Mech. Science, Vol. 1, pp. 45-66.

Attia, M. H. 2006, "Fretting fatigue and wear damage of structural components in nuclear power stations-Fitness for service and life management perspective," Tribolgy International, 39, 1294-1304.

Attia, M. H. 2006 , “On the fretting wear mechanism of Zr-alloys," Tribolgy International, $39,1320-1326$.

Au-Yang, M. K., 1998, "Flow-induced wear in steam generator tubes-prediction versus operational experience", ASME Journal of Pressure Vessel Technology, Vol. 120, pp. 138-143.

Au-Yang, M. K., 2000, "Joint and cross-acceptances for cross-flow induced Vibration-Part I: Theoretical and Finite Element Formulations", Journal of Pressure Vessel Technology, Vol. 122, pp.349-354.

Au-Yang, M. K., 2000, "The crossing frequency as a measure of heat exchanger support plate effectiveness", Proceedings of the $7^{\text {th }}$ International Conference on Flow- 
Induced Vibrations, FIV-2000, Lucerne, Switzerland, June 19-22, ISBN 90 5809, 1295, pp. 497-504.

Axisa, F., and Izquierdo, P., 1992, "Experiments on vibro-Impact-Dynamics of loosely supported tubes under harmonic excitation", Proceedings of International Symposium on Flow-Induced Vibration and Noise, Vol. 2, ASME, PVP. 242, eds., Paidoussis, M. J., Chen, S.S., and Steininger, D.A.

Axisa, F., Antunes, J. and Villard, B., 1990, "Random excitation of heat exchanger tubes by cross-flows", Journal of Fluid and Structures, Vol. 4, p. 321.

Axisa, F., Villard, B., Gibert, R. J., Hostroni, G., and Sundheimer, P., 1984, "Vibration of tube bundles subjected to air-water and steam-water cross-flow", ASME Winter Annual Meeting, p. 269.

Balsa, T. F., 1977, "Potential flow interactions in an array of cylinders in cross-flow", Journal of Sound and Vibration, Vol. 50, pp. 285-303.

Barrington, E. A., 1973, "Experience With acoustic Vibrations in tubular exchangers", Chem. Eng. Prog. Vol. 69. No. 7, pp. 62-68.

Blevins, R. D., 1974, "Fluid-elastic whirling of a tube row", ASME Journal of Pressure Vessel Technology, Vol. 96, pp. 263-267.

Blevins, R. D., 1977, "Flow-induced vibration", Van Nostrand Reinhold Company.

Blevins, R. D., 1979, "Fluid damping and the whirling instability of tube arrays", In flowInduced Vibrations (eds. S. S., Chen and M.D. Bernstein), New York: ASME, pp. 35-39.

Blevins, R. D., 1990, "Flow-Induced Vibration", Second Edition, Van Nostrand Reinhold Co., New York, N.Y.

Botros K. K., and Price G., 2000, "A case study of fluid -elastic instability of a large heat exchanger in a petrochemical process plant", Proceedings of the $7^{\text {th }}$ International Conference on Flow-Induced Vibrations, FIV-2000, Lucerne, Switzerland, June 19-22, ISBN 90 5809, 1295, pp. 489-496.

Brothman, A., Devore, A., Hollar, G.B., Horowitz, A., and Lee, H.T., 1974, "A tube vibration analysis method", AIChE Symposium Series No. 138, Vol. 70, pp. 190-204.

Burgreen, D., Byrnes, J. J., and Benforado, 1958, "Vibration of rods induced by water in parallel flow", Trans. ASME, Vol. 80, pp. 991-1003.

Carlucci, L. N., 1980, "Damping and hydrodynamic mass of a cylinder in simulated two-phase flow", Journal of Mech. Design, Vol. 102, pp. 597-602.

Carlucci, L. N., and Brown, J.D., 1983, "Experimental studies of damping and hydrodynamic mass of a cylinder in confined two-phase flow", ASME Journal of Vibration, Acoustics, Stress Reliability in Design, Vol. 105, pp.83-89.

Charpentier, J., and Payen, Th., 2000, "Prediction of wear work-rate and thickness loss in tube bundles under cross-flow by a probabilistic approach", Proceedings of the $7^{\text {th }}$ International Conference on Flow-Induced Vibrations, FIV-2000, Lucerne, Switzerland, June 19-22, ISBN 90 5809, 1295, eds., Ziada, S., and Staubli, T, pp.521-528.

Chen, S. S., 1983, "Instability mechanisms and stability criteria of a group of circular cylinders subject to cross-flow", Part-II: Numerical Results and Discussion, Journal of Vibration, Acoustics, Stress and Reliability in Design, Vol. 105, pp. 253-260.

Chen, S. S., 1984, "Guidelines for the instability flow velocity of tube arrays in cross-flow", Journal of Sound and Vibration, Vol. 93, pp. 439-455.

Chen, S. S., 1987, "A general theory for the dynamic instability of tube arrays in cross-flow", Journal of Fluids and Structures, Vol. 1, pp.35-53.

Chen, S. S., 1989, "Some issues concerning fluid-elastic instability of a group of cylinders in cross-flow", ASME Journal of Pressure Vessel Technology, Vol. 111, pp. 507-518. 
Chen, S. S., 1990, "Unsteady fluid forces and fluid-elastic vibration of a group of circular cylinders", Proceedings of ASME, Forum on unsteady flow (ed. Rathe, P.M.) ASME Publication, PVP, Vol. 204, pp. 1-6.

Chen, S. S., Zhu, S., and Cai, Y., 1995, "Experiment of chaotic vibration of loosely supported tube in cross-flow", ASME Journal of Pressure Vessel Technology, Vol. 117, pp. 204-211.

Chen, S.S., 1987, "Flow-induced vibration of circular cylindrical structures", Washington: Hemisphere Publishing.

Chen, S.S., and Wambsganss, M.W., 1974, "Design guide for calculating natural frequencies of straight and curved beams on multiple supports", ANL-CT-74-06, Components Technology Division, Argonne National Laboratory, Argonne, Illinois.

Chen, S.S., Zhu, S., and Jendrzejczyk, J.A., 1994, "Fluid damping and fluid stuffiness of a tube row in cross-flow", ASME Journal of Pressure Vessel Technology, Vol. 116, pp. 370-383.

Chen, Y. N., 1968, "Flow-induced vibration and noise in tube bank of heat exchangers due to von Karaman Streets", ASME Journal of Engineering Industry, Vol. 90, pp. 134-146.

Chenoweth, J. M., Chisholm, D., Cowie, R. C., Harris, D., Illingworth, A., Loncaster, J. F., Morris, M., Murray, I., North, C., Ruiz, C., Saunders, E. A. D., Shipes, K.V., Dennis Usher, and Webb, R. L., 1993, Heat Exchanger Design Handbook HEDH, Hemisphere Publishing Corporation.

Chenoweth, J.M., 1976, "Flow-Induced vibrations in shell-and-tube heat exchangers", Final report: Research on Heat Exchanger Tube Vibration, Contract No. EY-76-C-03-1273, Workshop, June 27-28, Pasadena, California.

Chu, I. C., Chung, H. J., \& Lee, S. 2011, “Flow-induced vibration of nuclear steam generator Utubes in two-phase flow," Nuclear Engineering and Design, 241, 1508-1515.

Chung, H. J., \& Chu, I. C. 2006, “Fluid-Elastic Instability Of Rotated Square Tube Array In An Air-Water Two-Phase Cross-Flow," Nuclear Engineering And Technology, Vol.38, No.1.

Coit, R. L., Ritland, P. D., Rabas, T. J., and Viscovich, P. W., 1974, "Moisture Separator Reheater: Entering the Second Decade, Two-phase flow in turbines", Short course, Rhode-SaintGenese, Belguim.

Collier, J., 1979, "Convective boiling and condensation", Oxford Science Publication.

Connors, H. J., and Parrondo, J., 1970, "Fluid-elastic vibration of tube arrays excited by crossflow", In Flow-Induced Vibration in Heat Exchangers (ed. D. D., Reiff), New York: ASME, pp. 42-56.

Dalton, C., 1980, "Inertia coefficients for riser configurations", In Energy Technology Conference and Exhibition, New Orleans, paper 80-Pet-21, York: ASME.

Dalton, C., and Helfinstein, R. A., 1971, "Potential flow past a group of circular cylinders", ASME Journal of Basic Engineering, Vol. 93, pp. 636-642.

Davis (Jr), F.J., and Hassan, Y. A., 1993, "A two-dimensional finite element method large eddy Simulation for application to turbulent steam generator flow".

Delaigue, D., and Planchard, J., 1986, "Homogenization of potential flow models for the dynamics of cylinder arrays in transient cross-flow", In ASME Symposium on FlowInduced Vibrations (ed S. S. Chen, J. C. Simonis and Y. S. Shin), PVP-Vol. 104, New York: ASME, pp. 139-145.

Eisinger, F. L., \& Sullivan, R. E. 2005, “Acoustic Vibration Behavior of Full Size Steam Generator and Tubular Heat Exchanger In-line Tube Banks," Proceedings of ASME Pressure Vessels \& Piping Division Conference, July 17- 21, Denver USA. 
Eisinger, F. L., \& Sullivan, R. E. 2007, “Acoustic resonance in a Package boiler and its solutionA case study," Journal of Pressure Vessel Technology, Vol. 129.

Eisinger, F. L., Sullivan, R. E., and Francis, J. T., 1994, "A review of acoustic vibration criteria compared to in-service experience with steam generator in-line tube banks", ASME Journal of Pressure Vessel Technology, Vol. 116, pp. 17-23.

Elliott, G.L., and Pick, R.J., 1973, "Calculation of natural frequencies of heat exchanger tubes", Proceedings of International Symposium on Vibration Problems in Industry", Keswick, U.K.

Endres, L. A. M., \& Möller, S. V. 2009, “Experimental Study of the Propagation of a Far-Field Disturbance in the Turbulent Flow through Square Array Tube Banks," Journal of the Braz. Soc. of Mech. Sci. \& Eng., Vol. XXXI, No. 3.

Erskine, J.B., and Waddington, W., 1973, "A review of some tube vibration failures in shell and tube heat exchangers and failure prediction methods", Proceedings of International Symposium on Vibration Problems in Industry, Keswick U.K., pp.1-9.

Feenstra, P. A., Judd, R. L., and Weaver, D.S., 1995, "Fluid-elastic instability in a tube array subjected to two-phase R-11 Cross-flow", Journal of Fluids and Structures, Vol. 9, pp. 747-771.

Feenstra, P. A., Weaver, D. S., \& Eisinger, F. L. 2006, “A Study Of Acoustic Resonance in Staggered Tube Array," Journal of Pressure Vessel Technology, Vol.128.

Feenstra, P. A., Weaver, D. S., and Judd, R. L., 1996, "Stability analysis of parallel triangular tube arrays subjected to two-phase cross-flow", Proceedings of CSME Conference, Manchester University.

Feenstra, P., Weaver, D.S., and Judd. R. L., 2000, "Modeling two-phase flow excited fluidelastic instability in tube arrays", Proceedings of the 7th International Conference on Flow-Induced Vibrations, FIV-2000, Lucerne, Switzerland, June 19-22, ISBN 90 5809, 1295, pp. 545-554.

Fisher, N.J., Ing, J. G., Pettigrew, M. J., and Rogers, R. J. 1991, "Fretting wear damage prediction in the inlet region of nuclear steam generators", Proceedings of I. Mech E. Conference, Paper C 416/053, London.

Fitzpatrick, J. A., 1986, "A design guide proposal for avoidance of acoustic resonance in in-line heat exchangers", ASME Journal of Vibration and Acoustics, Stress and Reliability in Design, Vol. 108, pp.296-300.

Frick, T. M., Sobek, T. E., and Reavis, J. R., 1984, "Overview on the development and implementation of methodologies to compute vibration and wear of steam generator tubes", Proceedings of the ASME Symposium on Flow-Induced Vibrations, Vol. 3, New Orleans.

Funakawa., M., Ishimatsu, T., Kumon, K., and Edakuni, K., 1989, "Excitation mechanism of fluid-elastic vibration in tube array", Trans. JSME, (in Japanese), Vol. 55, No. 519, C, p. 2718.

Govardhan, R., \& Williamson, C. H. K. 2000, "Modes of vortex formation and frequency response for a free vibrating cylinder'" Journal of Fluid Mechanics, 420, 85-130.

Goyder, H. G. D., 1988, "Fluid-elastic instability and buffeting of heat exchanger tube bundles due to single and two-phase flows", ASME Winter Annual Meeting, p. 151.

Gross, H. G., 1975, "Untersuchung aerodynamischer schwingungs- mechanismen und deren berucksichtigung bei der auslegung von rohrbundelwarmetauschern", Ph.D. Thesis, Technical University of Hannover.

Grotz, B. J., and Arnold, F. R., 1956, "Flow-induced vibration in heat exchangers", TN No. 31 to office of Naval Research from Stanford, A.D 104508. 
Hamakawa, H., \& Fukano, T. 2006, "Effect Of Flow Induced Acoustic Resonance On Vortex Shedding From Staggered Tube Arrays," JSME International Journal, Vol.49.

Hamakawa, H., \& Matsue, H. 2008, "Acoustic Resonance and vortex shedding from tube banks of Boiler Plant," Journal of Science and Technology, Vol.6, No. 3.

Hanson, R., \& Ziada, S. 2011, "Effect Of Acoustic Resonance On The Dynamic Lift Of Tube Arrays," Journal of Fluids and Structures, 27, 367-382.

Hanson, R., Mohany, A., \& Ziada, S. 2009, "Flow-excited Acoustic Resonance Of Two Side-BySide Cylinders In Cross-flow," Journal of Fluids and Structures, 25, 80-94.

Hara, F., 1987, "Vibration of a single row of circular cylinders subjected to two-phase bubble cross-flow", Proceedings of International Conference of Flow-Induced Vibration, No. E1, p. 203.

Hara, F., and Ohtani, I., 1981, "Study on vibration of a cylinder in two-phase flow", Trans. JSME, (in Japanese), Vol. 48, No. 431, C., p. 962.

Hassan, A. Marwan., Rogers, R. J., \& Gerber, A. G. 2011, “Damping-Controlled Fluidelastic Instability Forces In Multi-Span Tubes With Loose Supports," Nuclear Engineering and Design,241,2666-2673.

Hassan, M. A., Weaver, D. S., and Dokainish, M. A., 2000, "Modeling turbulence response of heat exchanger tubes in loose supports", Proceedings of the $7^{\text {th }}$ International Conference on Flow-Induced Vibrations, FIV-2000, Lucerne, Switzerland, June 19-22, ISBN 90 5809, 1295, eds., Zaida, S., and Staubli, T, pp.513-520.

Hassan, M., \& Hayder, M. 2008, "Modeling Of Fluidelastic Vibrations Of Heat Exchanger Tubes With Loose Supports," Nuclear Engineering and Design, 238, 2507-2520.

Hassan, Y. A., and Ibrahim, W. A., 1997, "Turbulence prediction in two- dimensional bundle flows using Large Eddy Simulation", Nuclear Technology, Vol. 119, pp. 11-28.

Heilker, W. J., and Vincent, R. Q., 1981, "Vibration in nuclear heat exchangers due to liquid and two-phase flow", ASME, Journal of Eng. Power, Vol. 103, p. 358.

Hofmann, P. J., and Schettler, T., 1989, "PWR steam generator tube fretting and fatigue wear", EPRI report NP-6341.

Inada, F., Kawamura, K., Yasuo, A., and Yoneda, K., 2000, "An experimental study on the fluid-elastic forces acting on a square tube bundle in two-phase cross-flow: the effect of vibration amplitude," Proceedings of FIV-2000, Lucerne, Switzerland, June 19-21, ISBN 905809 129 5, pp.555-568.

Ishihara, K., \& Kitayama, G. 2009, "Study on the Influence of Tube Arrays of Fluid Elastic Instability," Journal of System design and dynamics, 75,541-549.

Jones, A.T., 1970, "Vibration of beams immersed in liquid", Experimental Mechanics, pp. 84-88.

Jong, C., \& Jhung, M. J. 2008, "Flow-induced vibration and fretting-wear predictions of steam generator helical tubes," Nuclear Engineering and Design, 238, 890-903.

Kakac, S., \& Bon, B. 2008, "A Review of two-phase flow dynamic instabilities in tube boiling systems, International Journal of Heat and Mass Transfer, 51, 399-433.

Karaman, Th., 1912, "Uber den mechanismus des Widerstandes den ein bewegter Korper in einen Flussigkeit Erfahrt", Nachr. Konigl. Gesellschaft.

Khushnood, S., Khan, Z. M., Koreshi, Z U., and Rashid, H. U., 2000, "Dimensional analysis of vibration of tube bundle in cross-flow", Proceedings of $2^{\text {nd }}$ International Symposium on Mechanical Vibrations, ISMV-2000, eds. Chohan G.Y., and Ameer M., Sept. 25-28, Islamabad, Pakistan, pp. 534-550.

Khushnood. S, Zaffar M. Khan, M.Afzaal Malik, Qamar Iqbal, Sajid Bashir, Muddasar Khan, Zafarullah Koreshi, Mahmood Anwar Khan, Tahir Nadeem Malik \& Arshad Hussain Qureshi, 2010, "Modeling and Analysis of Thermal Damping in Heat 
Exchanger Tube Bundles", Journal of Nuclear Engineering and Design, Volume 240, Issue 7, July 2010, Pages 1906-1918

Khushnood, S., Khan, Z. M., Malik M. A., Koreshi, Z. U., and Khan, M. A., 2004, "A review of heat exchanger tube bundle vibrations in two-phase cross-flow", Journal of Nuclear Engineering and Design, Vol. 230, (3), pp. 233-251.

Khushnood, S., Khan, Z. M., Malik, M. A., Koreshi, Z., and Khan, M. A., 2003, "A review of heat exchanger tube bundle vibrations in two-phase cross-flow", 11th International Conference on Nuclear Engineering, ICONE-11, Tokyo, Japan.

Khushnood, S., Khan, Z.M., Malik, M.A., Koreshi, Z. U., Khan, M.A., 2002, "Vibration analysis of a multi-span tube in a bundle", Proceedings of $10^{\text {th }}$ International Conference on Nuclear Engineering, ICONE-10, March 14-18, Arlington Virginia, USA.

Kim, H. K., Lee, Y. H., \& Heo, S. P. 2006, "Mechanical and Experimental Investigation on nuclear rod fretting," Tribolgy International, 39, 1305-1319.

Kim, S., Alam, M. M., Sakamoto H., \& Zhou, Y. 2009, "Flow-induced Vibrations of Two Circular Cylinders in Tandem Arrangement. Part 1: Characteristics of Vibration," Journal of Wind Engineering and Industrial Aerodynamics, 97, $304-311$.

Kissel, J. H., 1972, "Flow-Induced vibrations in Heat Exchangers-A practical look", $13^{\text {th }}$ N. Heat Transfer Conference, Denver, AICh.E, paper 8.

Kissel, J. H., 1977, Private Correspondence".

Kumar, A. R., Sohn, H. C., \& Gowda, H. L. 2008, "Passive Control Of Vortex-Induced Vibrations: An Overview," Recent Patents on Mechanical Engineering 1, 1-11.

Lamb, H., 1932 and 1945, "Hydrodynamics", 6" ed., Cambridge University Press, 1932,and Dover, New York, 1945.

Lellouche, G. and Zollotar, B., 1982, "Mechanistic model for predicting two-phase void fraction for water in vertical tubes, channels, and rod bundles", Electric Power Research Institute (EPRI) Report NP-2246. SR.

Lever, J. H., and Weaver, D. S., 1986, "On the stability behavior of heat exchanger tube bundles", Part-II-numerical results and comparison with experiments, Journal of Sound and Vibration, Vol. 107, pp. 393-410.

Lian, H. Y., Noghrehkar, G., Chan, A. M. C., and Kawaji, M., 1997, "Effect of void fraction on vibrational behavior of tubes in tube bundle under two-phase cross-flow", Journal of Vibration and Acoustics, Vol. 119, pp. 457-463.

Liang, C., Papadakis, G., \& Luo, X. 2009, "Effect of tube spacing on the vortex shedding characteristics of laminar flow past an inline tube array: A numerical study," Computers \& Fluids, 38,950-964.

Lienhard, J. H., 1966, "Synopsis of lift, drag and vortex frequency data for rigid circular cylinders", Washington State University, College of Engineering Research Division, Bulletin, 300.

Lowery, R.L., and Moretti, P.M., 1975, "Natural frequencies and damping of tubes on multispan supports", 15 th National Heat Transfer Conference, AIChE, Paper No.1, San Francisco.

MacDuff, J. N., Feglar, R. P., 1957, "Vibration Design Charts" Trans. ASME, Vol. 79, pp. 1455-1474.

Mahon, J., \& Meskell, C. 2009, "Investigation of the Underlying Cause of the Interaction between Acoustic Resonance And Fluidelastic Instability In Normal Triangular Tube Arrays," Journal of Sound and Vibration, 324, 91 - 106.

Marn, J., and Catton, I., 1991, "Flow-induced vibrations of cylindrical structures using vorticity transport equation", Multidisciplinary Applications of Computational Fluid Dynamics, (ed, O. Baysal), FED-Vol. 129, New York: ASME, pp. 75-82. 
Marn, J., Catton, I., 1996, "On analysis of fluid-elastic instability in air-water mixture," Journal of Pressure Vessel Technology, Vol. 118, pp. 188-193.

Masatoshi Futakawa et. al., 1997, "Seismic test of a heat exchanger with a helically coiled tube bundle" Nuclear Technology, Vol. 118, pp. 83-88.

Minorsky, N., 1947, "Introduction to non-linear mechanics", Michigan: Ann Arbor.

Mirza, S., and Gorman, D.G., 1973, "Experimental and analytical correlation of local driving forces and tube response in liquid flow-induced vibration of heat exchangers", 2nd SMiRT conference, paper No. F6/5, pp.1-12.

Mitra, D., Dhir, V. K., \& Catton, I. 2009, “Fluid-Elastic Instability In Tube Arrays Subjected To Air-Water And Steam-Water Cross Flow," Journal of Fluids and Structures, 25, $1213-1235$.

Moretti, P. M., 1993, "Flow-induced vibrations in arrays of cylinders", Annual Review of Fluid Mechanics, Vol. 25, pp. 99-114.

Moretti, P. M., and Lowery, R. L., 1976, "Hydrodynamic inertia coefficients for a tubes surrounded by rigid tubes", ASME Journal of Pressure Vessel Technology, Vol. 120, pp. 190-193.

Mulcahy, T. J. 1980, "Fluid forces on rods vibrating in finite length annular regions", Journal of Applied Mech, Vol. 47, pp. 234-240.

Mureithi, N. W., \& Zhang, C., Rue, M., Pettigrew, M. J. 2005, “Fluidelastic Instability Tests On An Array Of Tubes Preferentially Flexible In The Flow Direction," Journal of Fluids and Structures, 21, 75-87.

Nakamura, T., and Fujita, K., 1988, "Study of flow-induced vibration of a tube array by a twophase flow", (3rd Report), Trans. JSME, (in Japanese), Vol. 54, No. 502, C, p. 1204.

Nakamura, T., Fujita, K., and Tsuge, A., 1993, "Two-phase cross-flow induced vibration of tube arrays", JSME International Journal, Series B, Vol. 36, No.3, pp. 429-438.

Nakamura, T., Fujita, K., Kawanishi, K., and Saito, I., 1986, "A study of the flow-induced vibration of a tube array by a two-phase flow" (2nd Report), Trans. JSME (in Japanese), Vol. 52, No, 483, C, p.2790.

Nakamura, T., Fujita, K., Shiraki, K., Kanazawa, H., and Sakata, K., 1982, "An experimental study on exciting force by two-phase cross-flow", Proceedings of ASME Pressure Vessel and Piping Conference, Vol. 63, p. 19.

Nakamura, T., Hirota, K., Tonomatsu, K., 2000, "Some problems on the estimation of flowinduced vibration of a tube array subjected to two-phase flow", Proceedings of FIV2000, Lucerne, Switzerland, June 19-21, ISBN 905809129 5, pp. 537-544.

Nakamura, T., Kawanishi, K., and Fujita, K., 1990, "Study on flow-induced vibration of a tube array by a two-phase flow", (4th Report), Trans. JSME, (in Japanese), Vol. 56, No. 525, C, p. 1164.

Nakamura, T., Murerithi, N.W., and Chen, S.S., 1997, "Fluid-elastic instability threshold for tube arrays in two-phase flow: A model incorporating temporal fluid force correction along the tube axis", Proceeding of ASME Winter Annual Meeting, Vol. 53-2, pp. 365-372.

Noghrehkar, R., Kawaji, M., and Chan, A. M. C., 1995, "An experimental study of local twophase parameters in cross-flow induced vibration in tube bundles", Proceedings of FIV-95, 6 th International Conference on Flow-Induced Vibration, ISBN 905410 547x, London, 10-12 April, pp. 373-382.

Oengoren, A., and Ziada, S., 1993, "Vortex shedding in an in-line tube bundle with large tube spacing", Journal of fluids and Structures, Vol. 7, pp 661-687. 
Oengoren, A., Ziada, S., 1995, "Vortex shedding, acoustic resonance and turbulent buffeting in normal triangle tube arrays" Proceedings of FIV-95, 6 $6^{\text {th }}$ International Conference on Flow-Induced Vibration, ISBN 905410 547x, ed, Bearman, P. W., pp. 295-313.

Ojalvo, I.U., and Newman, M., 1964, "Natural frequencies of clamped ring segments", Machine Design, pp. 219-222.

Owen P. R., 1965, "Buffeting excitation of boiler tube vibration", Journal of Mechanical Energy Science, Vol. 4, pp. 431-439.

Paidoussis, M. P. 2006, "Real-Life Experiences With Flow-Induced Vibration," Journal of Fluids and Structures, 22,741 - 755.

Paidoussis, M. P., 1965, "The amplitude of fluid induced vibration of cylinders in axial flow", AECL-2225.

Paidoussis, M. P., 1980, "Flow-induced vibrations in nuclear reactors and heat exchangers: Practical experiences and state of knowledge". In Practical Experiences with FlowInduced Vibrations (eds E. Naudascher and D. Rockwell), Berlin: Springer-Verlag, pp. 1-81.

Paidoussis, M. P., 1981, "Fluid-elastic vibration of cylinder arrays in axial and cross-flow: State of the art", Journal of Sound and Vibration, Vol. 76, pp. 329-360.

Paidoussis, M. P., 1982, "A review of flow-induced vibrations in reactors and reactor components", Nuclear Engineering and Design, Vol. 74, pp. 36-40.

Paidoussis, M. P., 1987, "A review of flow-induced vibrations in reactors and reactor components", Nuclear Engineering and Design, Vol. 74, pp. 31-60.

Paidoussis, M. P., 1987, "Flow-induced instabilities of cylindrical structures", Applied Mechanics Reviews, Vol. 40, pp. 163-175.

Paidoussis, M. P., and Li, G. X., 1992, "Cross-flow-induced chaotic vibrations of heat exchanger tubes impacting on loose supports", Journal of Sound and Vibration, Vol. 152 (2), pp. 305-326.

Paidoussis, M. P., Mavriplis, D., and Price, S. J., 1984, "A potential-flow theory for the dynamics of cylinder arrays in cross-flow", Journal of Fluid Mechanics, Vol. 146, pp. 227-252.

Papp, L., 1988, "Vibration of VVER NPP steam generator tubes," (in Czech), Jadera Energie, Vol. 34, No. 7, pp.249-259.

Papp, L., and Chen, S. S., 1994, "Turbulence-induced vibration of tube arrays in two phaseflow", Journal of Pressure Vessel Technology, Vol. 116, pp. 312-316.

Payen, T., Villard, B., and Jalaldeen, S., 1995, "Experimental validation of tube-to-support impact computations in cross-flow", Proceedings of FIV-95, 6 ${ }^{\text {th }}$ International Conference on Flow-Induced Vibration, ISBN 905410 547x, ed., Bearman, P.W, pp.383-292.

Peterka, F., 1995, "Impact Interaction of two-heat exchanger tubes", Proceedings of FIV-95, 6 $6^{\text {th }}$ International Conference on Flow-Induced Vibration, ISBN 905410 547x, ed., Bearman, P.W. pp.393-400.

Pettigrew, M. J., \& Taylor, C. E. 2003, "Vibration Analysis Of Shell-And-Tube Heat Exchangers: An Overview - Part 2: Vibration Response, Fretting-Wear, Guidelines," Journal of Fluids and Structures,18,485-500.

Pettigrew, M. J., \& Taylor, C. E. 2003, “Vibration Analysis Of Shell-And-Tube Heat Exchangers: An Overview -Part 1: Flow, Damping, Fluidelastic Instability," Journal of Fluids and Structures, 18, 469-483.

Pettigrew, M. J., and Gorman, D. J., 1973, "Experimental studies on flow-induced vibration to support steam generator design, Part III", Proceedings of International Symposium on Vibration Problems in Industry, AECL-5804. 
Pettigrew, M. J., and Taylor, C. E., 1994, "Two-phase flow-induced vibrations: An overview", Survey Paper, ASME Journal of Pressure Vessel Technology, Vol. 116, pp. 233-253.

Pettigrew, M. J., Goyder, H. G. D., Qiao, Z. L., and Axisa, F., 1986," Damping of multi-span heat exchanger tubes part I and II", Proceedings of Pressure Vessel and Piping Conference, ASME, 104, pp.81-87.

Pettigrew, M. J., Sylvestre, Y., Campagna, A. O., 1978, "Vibration analysis of heat exchanger and steam generator designs", Nuclear Engineering and Design, Vol. 48, pp. 99-115.

Pettigrew, M. J., Taylor, C. E., \& Kim, B.S., 1989, "Vibration of tube bundles in two-phase crossflow: part I: Hydrodynamic mass and damping", ASME Journal of Pressure Vessel Technology, Vol. 111, pp. 466-477.

Pettigrew, M. J., Taylor, C. E., and Kim, B. S., 2000, "The effects of tube bundle geometry on vibration in two-phase cross-flow", Proceedings of the Int. Conf. on FlowInduced Vibrations, FIV-2000, Lucerne, Switzerland, June 19-22, ISBN 905809129 5, pp. 561-568.

Pettigrew, M. J., Taylor, C. E., and Yasuo, A., 1994, "Vibration damping of heat exchanger tube bundles in two-phase flow", Welding Research Council, Bulletin No. 389, New York, pp. 1-41.

Pettigrew, M. J., Taylor, C. E., Jong, J. H., Currie, I. G., 1995, "Vibration of tube bundles in twophase freon cross-flow", Journal of Pressure Vessel Technology, Vol. 117, pp. 321-329.

Pettigrew, M. J., Tromp, J. H., and Mastorakos, J., 1985, "Vibration of tube bundles subjected to two-phase cross-flow", ASME Journal of Pressure Vessel Technology, Vol. 107, p. 335.

Pettigrew, M. J., Tromp, J. H., Taylor, C. E., and Kim, B.S., 1989, "Vibration of tube bundles in two-phase cross-flow, Part II, Fluid-Elastic Instability", Journal of Pressure Vessel Technology, Vol. 111, pp.478-487.

Pettigrew, M.J., Carlucci, L.N., Taylor, C.E., Fisher, N.J., 1991, "Flow-induced vibration and related technologies in nuclear components", Nuclear Engineering and Design, Vol. 131, pp.81-100.

Planchard, J., and Thomas, B., 1993, "On the dynamical stability of cylinders placed in crossflow", Journal of Fluids and Structures, Vol. 7, pp. 321-339.

Prasad, G. V. D., Pandey, M., \& Kalra, M. S. 2007, “Review Of Research On Flow Instabilities In Natural Circulation Boiling Systems," Progress in Nuclear Energy, 49, 429-451.

Price, S. J., 1995, "A review of theoretical models for fluid-elastic instability of cylinder arrays in cross-flow", Journal of Fluids and Structures, Vol. 9, pp. 463-518.

Quinn, E. P., 1962, "Vibration of fuel rods in parallel flow", GEAP-4059.

Rao, M. S. M., Steininger, D. A., and Eisinger, F. L., 1988, "Numerical simulation of fluid-elastic vibration and wear of multi-span tubes with clearance at supports", ASME Proceedings of $2^{\text {nd }}$ International Symposium on Flow-Induced Vibration and Noise, Vol. 5, eds., Paidoussis, M. J. et. al.

Remy, F.N., 1982, "Flow-induced vibration of tube bundles in two-phase cross-flow", Proceedings $3^{\text {rd }}$ Keswick International Conference on Vibration in Nuclear Plant, Paper 1.9, p. 135

Ribot, S. P., \& Blanchet, Y. 2007, “Buffeting lift forces and local air-water flow aspects around a rigid cylinder," International Journal of Multiphase Flow, 33, 1237-1254.

Roberts, B. W., 1962, "Low frequency, Self-excited vibration in a row of circular cylinders mounted in an air-stream", Ph.D Thesis, University of Cambridge.

Roberts, B. W., 1966, "Low frequency, aero-elastic vibrations in a cascade of circular cylinders", I. Mech. E. Mechanical Engineering Science Monograph, No. 4. 
Rogers, R. J., Taylor, C. E., and Pettigrew, M. J., 1984, "Fluid effects on multi-span heat exchanger tube vibration", ASME Journal of Pressure Vessel and Piping, ASME Publication H00316, Topics in Fluid Structure Interaction, pp. 17-26.

Rubiolo, P. R. 2006, "Probabilistic prediction of fretting-wear damage of nuclear fuel rods," Nuclear Engineering and Design, 236, 1628-1640.

Rubiolo, P. R., \& Young, M. Y. 2009, “On the factors affecting the fretting-wear risk of PWR fuel assemblies," Nuclear Engineering and Design, 239, 68-79.

Schrage, D., 1988, "Two-phase pressure drop in vertical cross-flow across horizontal tube bundle", AIChE Journal, Vol. 34, No.1, pp. 107-115.

Shin, Y. S., and Wambsganss, M.W., 1975, "Flow-induced vibrations in LMFBR steam generators: A state-of-the-art review", ANL-75-16, Report for the U.S. Energy Research, and Development Administration, Argonne National Laboratory, Argonne, Illinois.

Sim, W. G., \& Park, M. Y. 2010, "Fluid-elastic Instability of Normal Square Tube Bundles in Two-Phase Cross Flow," Proceedings of the 18th International Conference on Nuclear Engineering, May 17- 21, Xi'an, China.

Simpson, F. J., and Hartlen R. T., 1974, "Wind tunnel determination of fluid-elastic vibration thresholds for typical heat exchanger tube patterns", Ontario Hydro Research Division Report, 74-309-K.

Sipvack, H. M., 1946, "Vortex frequency and flow pattern in the wake of two parallel cylinders at varied spacing normal to an air stream", Journal of the Aeronautical Sciences, pp. 289-301.

Smith, S., 1968, "Void fractions in two-phase flow: A correlation based upon an equal velocity head model," Proc. Inst. Mech. Eng.

Standards of Tubular Exchanger Manufacturers Associate 1988, 7th ed., TEMA, New York.

Standards of Tubular Exchanger Manufacturers Association, 1978, $6^{\text {th }}$ ed., TEMA, New York.

Stokes, G. G., 1843, "On some cases of fluid motion", Proceedings, Cambridge Philosophical Society, Vol. 8, pp. 105-137.

Taitel, Y., Barnea D., and Dukler, A., 1980, "Modeling flow pattern transition for steady upward gas-liquid flow in vertical tubes", Al ChE Jl., Vol. 26, pp. 345-354.

Tanaka, H., \& Takahara, S., 1980, "Unsteady fluid dynamic force on tube bundle and its dynamic effect on vibration", In Flow-Induced Vibration of Power Plant Components, (ed M. K. Au-Yang), PVP-Vol. 41, New York: ASME, pp. 77-92.

Tanaka, H., \& Takahara, S., 1981, "Fluid-elastic vibration of tube array in cross-flow", Journal of Sound and Vibration, Vol. 77, pp. 19-37.

Taylor, C. E., 1992, "Random excitation forces in tube arrays subjected to two-phase crossflow", Proceedings of WAM-1992, International Symposium on Flow-Induced Vibration and Noise, Vol. 1, HTD- Vol. 230, pp. 89-107.

Taylor, C. E., and Pettigrew, M. J., 2000, "Effect of flow-regime and void fraction on tube bundles vibration", Proceedings of FIV-2000, Lucrene, Switzerland, June 19-21, ISBN 905809 1295, pp. 529-536.

Taylor, C. E., Boucher, K. M., and Yetisir, M., 1995, "Vibrational impact forces due to twophase cross-flow in u-bend of nuclear steam generators", Proceedings of FIV-95, $6^{\text {th }}$ International Conference on Flow-Induced Vibration, ISBN 905410 547x, pp. 401-411.

Taylor, C. E., Currie, I. G., Pettigrew, M.J. and Kim, B. S., 1989, "Vibration of tube bundles in two-phase cross-flow, Part 3: Turbulent Induced Excitation", ASME Journal of Pressure Vessel Technology, Vol. 111, pp.488-500.

Taylor, C. E., Pettigrew, M. J., Dickinson, T. J., Currie, I.G., and Vidalou, P., 1998, "Vibration damping in multi-span heat exchanger tubes", ASME Journal of Pressure Vessel Technology, Vol. 120, pp. 283-289. 
TEMA Standards, $8^{\text {th }}$ edition, Flow-Induced Vibration Program, Version 1.10, Tubular Exchangers Manufacturers Association Inc

Thomas, D. G., and Kraus, K. A., 1964, "Interaction of vortex streets", Journal of Applied Physics, Vol. 35, p. 3458-3459.

Thorngren, J. T., 1970, "Predict heat exchanger tube damage", Hydro Carbon process, Vol. 49 (4), pp. 129-131.

Timoshenko, G. P., 1955, "Vibration Problems in Engineering", 3rd edition, D. Van Nortrand Co., Inc, Princeton, N.J., pp. 324-342.

Ulbrich, R., Mewes, D., 1994, "Vertical, upward gas liquid two-phase flow across a tube bundle", International Journal of Multiphase Flow, Vol. 20, pp. 249-272.

Ulbrich, R. N., \& Mewes, D., 1997, "Recognition of flow pattern for two-phase flow across tube bundle", $4^{\text {th }}$ World Conference on Experimental Heat Transfer, Fluid Mechanics and Thermodynamics, Brussels, June 2-6.

Vander Hoogt, P. J. M., and Van Campen, D. H., 1984, "Self-induced instabilities of parallel tubes in potential cross-flow", In Proceedings ASME Symposium on Flow-induced Vibrations, Vol. 2: Vibration of Arrays of Cylinders in Cross Flow (eds. M. P. Paidoussis, M. K., Au-Yang and S. S., Chen), New York: ASME, pp. 53-66.

Wambsganss, M. W., Jendrzejczyk, J. A., and France, D. M., 1992, "Two-phase flow and pressure drop in flow passages of compact heat exchangers", SAE Technical Paper Series 920550.

Wambsganss, M. W., Chen, S.S., and Jendrzejcyk, J.A., 1974, "Added mass and damping of a vibrating rod in confined viscous fluid" ANL-CT-75-08, Report, Argonne National Laboratory, Argonne, Illinois.

Wang, Y. Q., Jackson, P., \& Phaneuf, T. J. 2006, “Turbulent Flow Through a Staggered Tube Bank," Journal Of Thermophysics And Heat Transfer, Vol. 20, No. 4.

Weaver, D. S. and J.A. FitzPatrick, 1988, "A review of cross-flow-induced vibrations in heat exchanger tube arrays", Journal of Fluids and Structures, Vol. 2, pp. 73-93.

Weaver, D. S., 1993, "Vortex shedding and acoustic resonance in heat exchanger tube arrays", Technology for the 90's, ASME Special Publication, New York, pp. 776-810.

Weaver, D. S., and Fitzpatrick, J. A., 1988, "A review of flow-induced vibrations in heat exchangers", Journal of Fluids and Structures, Vol. 2, pp. 73-93.

Weaver, D. S, 1993, "An introduction to flow-induced vibrations "lecture notes, BHRA", The Fluid Engineering Center, Cranfield, Bedford, England.

Williamson, C. H. K., \& Govardhan, R. 2008, “A Brief Review Of Recent Results In VortexInduced Vibrations," Journal of Wind Engineering and Industrial Aerodynamics, $96,713-735$.

Zaida, S., Oengoren, A., and Buhlmann, E. T., On acoustical resonance in tube arrays Part-I: Experiments", International Symposium on Flow-induced Vibrations and Noise, Vol. 3, Winter Annual Meeting, Chicago, IL, ASME, pp. 219-243.

Zhou, T., and Rogers, R. J., 1997, "Simulation of two-dimensional squeeze film and solid contact forces acting on a heat exchanger tube", Journal of Sound and Vibration, Vol. 203(4), pp. 621-639.

Ziada, S., and Oengoren, A., 1992, "Acoustic and mechanical resonances in tube bundles" Report No. SAK- TB92-063, Sulzer Innotec Limited Winterthur, Switzerland.

Zuber, N., Findlay, J., 1965, "Average volumetric concentration in two-phase flow systems", Journal of Heat Transfer, pp. 453-468.

Zukauskas, A., Ulinskas, R. and Katinas, V. 1987, "Fluid dynamics and flow-induced vibrations of tube banks", New York: Hemisphere Publishing. 


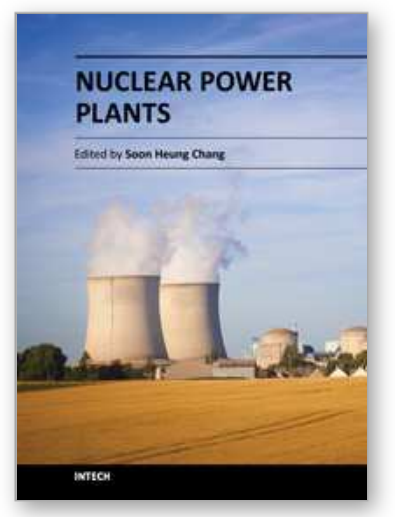

\author{
Nuclear Power Plants \\ Edited by Dr. Soon Heung Chang
}

ISBN 978-953-51-0408-7

Hard cover, 340 pages

Publisher InTech

Published online 21, March, 2012

Published in print edition March, 2012

This book covers various topics, from thermal-hydraulic analysis to the safety analysis of nuclear power plant. It does not focus only on current power plant issues. Instead, it aims to address the challenging ideas that can be implemented in and used for the development of future nuclear power plants. This book will take the readers into the world of innovative research and development of future plants. Find your interests inside this book!

\title{
How to reference
}

In order to correctly reference this scholarly work, feel free to copy and paste the following:

Shahab Khushnood, Zaffar Muhammad Khan, Muhammad Afzaal Malik, Zafarullah Koreshi, Muhammad Akram Javaid, Mahmood Anwer Khan, Arshad Hussain Qureshi, Luqman Ahmad Nizam, Khawaja Sajid Bashir, Syed Zahid Hussain (2012). Cross-Flow-Induced-Vibrations in Heat Exchanger Tube Bundles: A Review, Nuclear Power Plants, Dr. Soon Heung Chang (Ed.), ISBN: 978-953-51-0408-7, InTech, Available from: http://www.intechopen.com/books/nuclear-power-plants/cross-flow-induced-vibrations-in-heat-exchanger-tubebundle-a-review

\section{INTECH}

open science | open minds

\section{InTech Europe}

University Campus STeP Ri Slavka Krautzeka 83/A 51000 Rijeka, Croatia Phone: +385 (51) 770447 Fax: +385 (51) 686166 www.intechopen.com

\section{InTech China}

Unit 405, Office Block, Hotel Equatorial Shanghai No.65, Yan An Road (West), Shanghai, 200040, China 中国上海市延安西路65号上海国际贵都大饭店办公楼405单元 Phone: +86-21-62489820

Fax: +86-21-62489821 
(C) 2012 The Author(s). Licensee IntechOpen. This is an open access article distributed under the terms of the Creative Commons Attribution 3.0 License, which permits unrestricted use, distribution, and reproduction in any medium, provided the original work is properly cited. 